\title{
Biodegradable nanoparticle delivery of inactivated swine influenza virus vaccine provides heterologous cell-mediated immune response in pigs
}

\author{
Santosh Dhakal ${ }^{\mathrm{a}}$, Jagadish Hiremath ${ }^{\mathrm{a}}$, Kathryn Bondra ${ }^{\mathrm{a}}$, Yashavanth S Lakshmanappa ${ }^{\mathrm{a}}$, Duan- \\ Liang Shyu ${ }^{\mathrm{a}}$, Kang Ouyang ${ }^{\mathrm{a}}$, Kyung-il Kang ${ }^{\mathrm{a}}$, Basavaraj Binjawadagi ${ }^{\mathrm{a}}$, Jonathan Goodman ${ }^{\mathrm{b}}$, \\ Kairat Tabynov ${ }^{\mathrm{c}}$, Steven Krakowka ${ }^{\mathrm{d}}$, Balaji Narasimhan ${ }^{\mathrm{b}}$, Chang-Won Lee ${ }^{\mathrm{a}}$ and \\ Gourapura J. Renukaradhya ${ }^{\mathrm{a} *}$
}

${ }^{a}$ Food Animal Health Research Program, Ohio Agricultural Research and Development Center, 1680 Madison Avenue, Wooster, OH 44691, USA, and Department of Veterinary Preventive Medicine, College of Veterinary Medicine, The Ohio State University, Columbus, OH 43210, USA. ${ }^{b}$ Department of Chemical and Biological Engineering, Iowa State University, Ames, IA

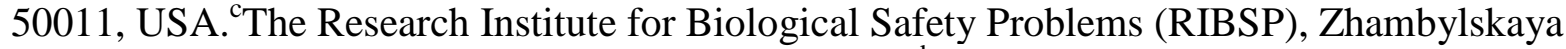
oblast, Gvardeiskiy, 080409 Republic of Kazakhstan. ${ }^{\mathrm{d}}$ The Department of Veterinary Biosciences, College of Veterinary Medicine, The Ohio State University, 1925 Coffey Road, Columbus, OH, USA.

*Corresponding author:

Dr. Gourapura J. Renukaradhya

Food Animal Health Research Program,

Ohio Agricultural Research and Development Center

The Ohio State University, 1680 Madison Avenue, Wooster, OH 44691

Phone: 330-263-3748

Fax: 330-263-3677

E-mail: gourapura.1@osu.edu 


\section{ABSTRACT}

Swine influenza virus (SwIV) is one of the important zoonotic pathogens. Current flu vaccines have failed to provide cross-protection against evolving viruses in the field. Poly lactic-coglycolic acid (PLGA) is a biodegradable FDA approved polymer and widely used in drug and vaccine delivery. In this study, inactivated SwIV H1N2 antigens (KAg) encapsulated in PLGA nanoparticles (PLGA-KAg) were prepared, which were spherical in shape with 200 to $300 \mathrm{~nm}$ diameter, and induced maturation of antigen presenting cells in vitro. Pigs vaccinated twice with PLGA-KAg via intranasal route showed increased antigen specific lymphocyte proliferation and enhanced the frequency of T-helper/memory and cytotoxic T cells (CTLs) in peripheral blood mononuclear cells (PBMCs). In PLGA-KAg vaccinated and heterologous SwIV H1N1 challenged pigs, clinical flu symptoms were absent, while the control pigs had fever for four days. Grossly and microscopically, reduced lung pathology and viral antigenic mass in the lung sections with clearance of infectious challenge virus in most of the PLGA-KAg vaccinated pig lung airways was observed. Immunologically, PLGA-KAg vaccine irrespective of not significantly boosting the mucosal antibody response, it augmented the frequency of IFN- $\gamma$ secreting total T cells, T-helper and CTLs against both H1N2 and H1N1 SwIV. In summary, inactivated influenza virus delivered through PLGA-NPs reduced the clinical disease and induced cross-protective cell-mediated immune response in a pig model. Our data confirmed the utility of a pig model for intranasal particulate flu vaccine delivery platform to control flu in humans.

Keywords: Swine influenza virus, PLGA nanoparticles, intranasal vaccination, pigs, immune response, $\mathrm{T}$ cells 


\section{Introduction}

Swine influenza is an acute respiratory infection of pigs caused by influenza A virus (IAV) of Orthomyxoviridae family. At present H1N1, H1N2 and H3N2 subtypes of IAV cause majority of infection in pigs. Owing to the presence of both avian $(\alpha 2,3 \mathrm{Gal})$ and human $(\alpha 2,6$ Gal) IAV receptors, pigs can potentially act as mixing vessel for different IAV $[1,2]$. Acute clinical signs in influenza infected pigs include high fever, anorexia, respiratory distress, nasal discharge and coughing. Therefore, influenza in pigs causes significant economic loss to the porcine industry through morbidity, loss of body weight gain, increased time to market, susceptibility to secondary bacterial and viral infections like mycoplasma and porcine reproductive and respiratory syndrome (PRRS), medication and veterinary expenses [3, 4]. Some of the swine influenza viruses (SwIV) can also be transmitted from pigs to humans (zoonotic) creating public health risk. For example, the 2009 pandemic H1N1 swine influenza virus infected approximately $20 \%$ of the global population and caused around 200,000 deaths [5-9], in addition to approximately 500,000 deaths due to seasonal annual influenza infection [10, 11].

Vaccination is one of the most effective means of controlling influenza, and swine influenza vaccines are commercially available to use in pigs. Due to high mutation rates in circulating influenza viruses in animals the efficacy of commercial vaccines in the field is always poor $[12,13]$. Commercial multivalent vaccines coadministered with an adjuvant intramuscularly as prime-boost strategy provide homologous, but weak heterologous protection. Intramuscular vaccination does not induce the required levels of local mucosal antibody and cell-mediated immune responses; moreover, there are reports of inactivated vaccine associated enhanced respiratory disease [14-16]. Thus, persistent economic burden of swine influenza in pig industry 
and its potential risk of zoonotic transmission to humans warrants the development of broadly cross-protective vaccine platforms.

Biodegradable and biocompatible polymer, poly(lactic-co-glycolic acid) (PLGA), based nanoparticles (PLGA-NPs) are being widely used for controlled vaccine and drug delivery [1719]. PLGA has been approved by Food and Drug Administration (FDA) and European Medicines Agency (EMA) for use in humans (including children) as a vehicle. PLGA-NPs encapsulated vaccine antigens are preserved inside the particles from degradation for a long period of time (4-8 weeks) under physiological conditions, which is critical when vaccine is delivered to mucosal sites; while the benefit of slow release of the cargo in vivo when administered by parenteral route helps in prolonged immune activation [20]. Moreover, PLGANPs assist in internalization of the antigen by professional antigen presenting cells (APCs) such as dendritic cells (DCs), macrophages (M $\phi s)$ and B cells. PLGA-NPs also facilitate antigen processing and presentation by APCs to naive lymphoctyes [21]. PLGA-NPs of size up to 500 $\mathrm{nm}$ are readily uptaken by APCs and induce production of virus neutralizing antibodies as well as cell-mediated immune response in mice models [22-24]. Antigens encapsulated in PLGA-NPs and delivered by intranasal route are protected from proteolytic degradation at mucosal surfaces and readily uptaken by immune cells at the mucosal sites of the respiratory tract, and thus has the potential of inducing strong mucosal immune response. Thus, particulate delivery of influenza vaccine can be a better alternative over existing parenteral vaccine delivery platforms to effectively control infectious diseases [25].

A previous vaccine trial carried out in our laboraory has shown that PLGA-NPs encapsulated porcine reproductive and respiratory syndrome virus (PRRSV) coadministered intranasally with a potent adjuvant significantly reduced challenge heterologous virus induced 
lung pathology, virus load and protected pigs against the disease [26]. Recently, we found that PLGA-NPs encapsulated highly conserved total of five H1N1 IAV T and B cell peptides cocktail administered intranasally without an adjuvant elicited peptide specific $\mathrm{T}$ cell response, but not the antibody response, and still helped in the clearance of a heterologous challenge virus from the lungs of pigs [27]. These findings suggested that the whole inactivated influenza viral antigens delivered in PLGA-NPs vehicle will have the potential to further enhance the breadth of immunity and protection against influenza in pigs. Therefore, in this study we prepared and evaluated the immunogenicity and efficacy of PLGA-NPs encapsulated inactivated SwIV (PLGA-KAg) vaccine in a heterologous virus challenge trial in pigs. Our results suggested that intranasal administration of PLGA-KAg vaccine induced strong $\mathrm{T}$ cell response against both homologous and heterologous viruses detected at both pre-challenge as well as post-challenge, and substantaily reduced the heterologous challenge virus induced clinical disease, lung pathology and virus load in the lungs.

\section{Materials and methods}

\subsection{Cells and viruses}

A stable mycoplasma-free Madin-Darby canine kidney epithelial cells (MDCK, CRL2285, ATCC, VA) were maintained in Dulbecco's modified eagle medium (DMEM) (Gibco) supplemented with $10 \%$ fetal bovine serum (Sigma) and antibiotic-antimycotic (Gibco) at $37^{0} \mathrm{C}$ in $5 \% \mathrm{CO}_{2}$ incubator. Field isolates of swine influenza virus (SwIV), SW/OH/FAH10-1/10

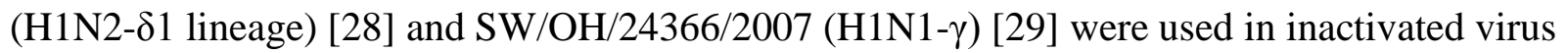
vaccine preparation and challenge infection of pigs, respectively. The H1N2 virus (SW/OH/FAH10-1/10) has NP and M genes derived from the 2009 pandemic H1N1 [28], and 
the A/swine/Ohio/24366/07 was a zoonotic virus isolated from swine and also was shown at the CDC to have $100 \%$ identical genome sequence to the human virus associated in the Ohio county fair [29]. SwIV stocks (passage 3) were obtained from the repository at FAHRP, Wooster, Ohio. Both viruses were propagated on MDCK cells by infecting at MOI 0.005 and maintaining in serum free DMEM supplemented with $1 \mu \mathrm{g} / \mathrm{ml}$ TPCK-trypsin (Sigma, MO).

\subsection{Vaccine preparation}

SwIV isolate SW/OH/FAH10-1/10 (H1N2- $\delta 1)$ culture fluid was harvested and clarified to remove cell debris by centrifugation at $2000 \mathrm{xg}$ for $30 \mathrm{~min}$ and subjected to 10 -fold concentration using Pellicon-2 cassette filtration (Millipore, MA) followed by ultracentrifugation using Optima ${ }^{\mathrm{TM}}$ L-100XP ultracentrifuge (Beckman Coulter) with $20 \%$ sucrose cushion at 107, $000 \mathrm{xg}$ for $4 \mathrm{hrs}$ without break. Virus pellet was suspended in PBS containing protease inhibitor (Sigma, MO), titrated and stored at $-80^{\circ} \mathrm{C}$. Virus was inactivated using binary ethyleneimine (BEI) (Sigma, MO) by treating with $10 \mathrm{mM} \mathrm{BEI}$ for $6 \mathrm{hrs}$ at $37^{\circ} \mathrm{C}$ followed by treatment with $10 \mathrm{mM}$ sodium thiosulphate (Sigma, MO) for additional $2 \mathrm{hrs}$ at $37^{0} \mathrm{C}$ to neutralize the unused BEI, and the virus inactivation was confirmed in MDCK cells. Total protein concentration in the virus pellet was estimated using micro BCA protein assay kit (Thermo Scientific, MA) as per the manufacturer's protocol.

Inactivated SwIV antigen (KAg) was encapsulated in PLGA-NPs by water/oil/water double emulsion solvent evaporation technique as described previously [26, 27]. Briefly, $5 \mathrm{mg}$ of $\mathrm{KAg}$ in $500 \mu \mathrm{l}$ PBS and $250 \mu 1$ of $2 \%(\mathrm{w} / \mathrm{v}$ ) polyvinyl alcohol (PVA) with protein stabilizers, 50 $\mu 1$ of $20 \%$ sucrose (w/v) and $50 \mu \mathrm{l}$ of $20 \% \mathrm{Mg}(\mathrm{OH}) 2(\mathrm{w} / \mathrm{v})$, were emulsified in $180 \mathrm{mg}$ of PLGA polymer solution in $4.5 \mathrm{ml}$ of dichloromethane using high intensity ultrasonic processor (Sonics and Materials Inc., CT) for $30 \mathrm{sec}$ at duty cycle $30 \%$ and output control 3. The resulting water- 
in-oil (w/o) primary emulsion was poured into a mixture of $23 \mathrm{ml} 2 \% \mathrm{w} / \mathrm{v}$ PVA (Sigma) and 2 $\mathrm{ml} 12.5 \%(\mathrm{w} / \mathrm{v}$ ) polaxmer 188 (Sigma, MO) to form an aqueous solution. The mixture was divided equally into two tubes and emulsified again by sonication for $60 \mathrm{sec}$ to obtain secondary w/o/w emulsion, and it was emulsified by magnetic stirring overnight at $400 \mathrm{rpm}$ in cold $\left(4^{\circ} \mathrm{C}\right)$ to allow evaporation of the organic solvents. Resulting polymeric particles were washed thrice using cold sterile Milli-Q water by centrifugation at 10,976 xg (Beckman Coulter, FX6100 rotor) for 30 min. Finally, PLGA-NP pellet was suspended in 5\% sucrose in milli Q water, frozen at $80^{\circ} \mathrm{C}$ for $30 \mathrm{~min}$, freeze-dried (Labconco, MO) for $18-20 \mathrm{hrs}$ and aliquots were stored at $-20^{\circ} \mathrm{C}$. The inactivated KAg encapsulated in PLGA-NP is henceforth called as PLGA-KAg.

\subsection{Characterization of PLGA-KAg}

Particle size and morphology was examined by a FEI Quanta 250 scanning electron microscope (SEM, Kyoto, Japan) after coating with $2 \mathrm{~nm}$ of iridium using a Quorum Q150TS sputter coater (Lewes, UK). Nanoparticle size distribution was characterized using ImageJ image software (National Institutes of Health, MD) with an average of 200 nanoparticles per image. Quasi-elastic light scattering experiments (QELS) were used to measure the $\zeta$-potential of the nanoparticles using a Zetasizer Nano (Malvern Instruments Ltd., Worchester, UK). NPs $100 \mu \mathrm{g}$ were suspended in cold nanopure water and thoroughly dispersed using a probe sonicator (Ultra Sonic Processor VC 130PB, Sonics Vibra Cell, CT) before analysis. Three independent measurements were taken in order to get an average $\zeta$-potential value. Protein encapsulation efficiency and in vitro protein release profile at days $0,1,3,5,7,10,15,20,25$ and 30 were estimated and expressed as the cumulative percentage release of SwIV antignes at each time point using the methods described previously [26, 27].

2.4 In vitro activation of APCs by PLGA-KAg 
Monocyte derived dendritic cells (MoDCs) and alveolar macrophages were used as APCs for in vitro activation study. To generate MoDCs - (i) peripheral blood mononuclear cells were isolated from blood; (ii) CD172a $\mathrm{a}^{+}$myeloid cells were magnetically sorted from PBMCs using MACS Large cell column (Miltenyi Biotec, CA); and (iii) cells were treated with cytokines GMCSF (50 ng/ml) and IL-4 (25 ng/ml) (Kingfisher biotech, MN) for a week. As a source of alveolar macrophages, porcine bronchoalveolar lavage (BAL) cells were collected by infusion of PBS through trachea of heatlhy 6-8 week old pigs and collected the lavage fluid. Porcine BAL cells constitutes over $90 \%$ of macrophages [30, 31], like in other species of animals [32]. BAL cells (0.5 million) and MoDCs (0.1 million) were cultured with: (i) RPMI enriched with $10 \%$ FBS (E-RPMI) only; (ii) KAg ( $2 \mu \mathrm{g} / \mathrm{ml})$ in E-RPMI; (iii) PLGA-KAg (KAg $2 \mu \mathrm{g} / \mathrm{ml}$ equivalent of NPs); or (iv) PLGA-NPs (equivalent weight of NPs) in E-RPMI for $24 \mathrm{hrs}$ at $37^{\circ} \mathrm{C}$ in a $5 \%$ $\mathrm{CO}_{2}$ incubator. Stimulated cells were fixed and immunostained using CD172a (Southernbiotech, $\mathrm{AL}$ ) and CD152-muIg (Ancell, MN) antibodies, and 50,000 events were acquired by flow cytometry (BD FACS Aria II, BD Pharmingen CA) and analyzed using the FlowJo software (Tree Star, OR). CD152-muIg is a human specific antibody shown to cross-react with porcine APCs costimulatory molecules CD80/86 [33].

\subsection{Experimental design, vaccination, viral challenge and collection of samples}

Caesarian delivered colostrum deprived (CDCD) and bovine colostrum fed Large WhiteDuroc crossbred 4-5 weeks old piglets $(\mathrm{n}=32)$ were raised in our BSL2 facility at OARDC as described previously [27] and used in our study. Piglets were confirmed seronegative for hemagglutination (HI) antibodies against influenza virus subtypes H1N1 and H1N2 and were randomly divided into 4 experimental groups ( $\mathrm{n}=7-9$ pigs/group) (Table 1). For randomization, piglets derived from 4 sows on the same day were raised in a temperature regulated BSL2 
isolation room in 4 elevated crates. At 4 weeks of age piglets were randomly assigned in to 1 of 4 groups (Table 1), wherein every experimental group had piglets from all the 4 sows (i.e., 1 to 3 pigs of each sow). Animals were allowed an additional week of acclimation before used in the study. Pigs were maintained, inoculated and euthanized in accordance with the standards of the Institutional Laboratory Animal Care and Use Committee at The Ohio State University. Animals were vaccinated at 4-5 weeks, boosted after 3 weeks and challenged after 2 weeks of boost. Pigs were vaccinated with $10^{7} \mathrm{TCID}_{50}$ equivalent of H1N2 KAg or PLGA-KAg suspended in $2 \mathrm{ml}$ DMEM and delivered intranasally as a mist using a multidose delivery device (Prima Tech USA, NC) (Fig. 3A), and challenged using the heterologous H1N1 SwIV $\left(6 \times 10^{6}\right.$ TCID $\left._{50}\right)$ in $2 \mathrm{ml}, 1 \mathrm{ml}$ administered intranasally and another $1 \mathrm{ml}$ intratracheally [29].

Plasma samples were collected at days post-vaccination (DPV) 0, 21 and 35. From the day of challenge to euthanasia, pigs were observed twice daily for clinical signs and rectal temperature was recorded daily. Nasal swab samples were collected at days post-challenge (DPC) 4 and 6 in $2 \mathrm{ml}$ DMEM containing antibiotics. Pigs were euthanized at DPC 6 and during necropsy the lungs were examined and scored for the gross lesions [34]. A board certified veterinary pathologist involved in scoring the lung lesions of pigs was blinded by not providing any details of the experimental pig groupings. Blood and BAL fluid sampels were collected and aliquots of plasma and BAL fluid stored at $-80^{\circ} \mathrm{C}$. BAL fluid was collected by infusing $20 \mathrm{ml}$ PBS (containing 2\% EDTA) through the trachea and collected the fluid after gentle massaging of all the lung lobes. For preparation of lung lysate, $1 \mathrm{gm}$ of lung tissue from the right apical lobe was homogenized in 3ml DMEM (with protease inhibitor) and supernatant was collected after centrifugation and aliquots were stored at $-80^{\circ} \mathrm{C}$ as described previously [35]. Lung tissue samples were collected by one person uniformly from the identical regions of the right apical, 
cardiac and diaphragmatic lobes of each pig and fixed in $10 \%$ neutral buffered formalin for detailed histopathological and immunohistochemical evaluations of every tissue section. Average scores of all the lung lobes sections were considered for final grading as described previously $[16,36]$. PBMCs were isolated at DPC 0 and 6 and used in cell proliferation assays upon stimulation with SwIV as well as used in flow cytometry analysis

\subsection{Cell proliferation and flow cytometry assays}

At DPC 0 antigen specific $\mathrm{T}$ cells proliferation was carried out in PBMCs using cell titer 96 aqueous non-radioactive proliferation assay kit (Promega, WI) as per the manufacturer's instructions. Briefly, 1x10 $\mathrm{PBMCs} /$ well were plated in a 96 well U-bottom plate (Greiner bioone, NC) in $100 \mu 1$ of E-RPMI medium. Both the SwIV H1N2 and H1N1 used in the vaccine preparation and pig challenge, respectively, were used at MOI of 0.1 in $100 \mu \mathrm{l}\left(1 \times 10^{5}\right.$ $\mathrm{TCID}_{50} /$ well) for stimlation. Plates were incubated at $37^{\circ} \mathrm{C}$ in a $5 \% \mathrm{CO}_{2}$ incubator, and after 72 hrs plates were centrifuged at $2000 \mathrm{rpm}$ for $2 \mathrm{~min}$ and the supernatant was collected, and added $100 \mu 1$ E-RPMI and $20 \mu 1$ MTS + PMS solution to the cell pellet and incubated for another 4 hrs at $37^{\circ} \mathrm{C}$ in a $5 \% \mathrm{CO}_{2}$ incubator. The optical density (OD) at $490 \mathrm{~nm}$ was recorded using the ELISA plate reader (Spectramax plus384, Molecular Devices, CA). Stimulation index (SI) was determined by dividing OD of stimulated PBMCs from OD of cell control of the same pig, and average SI values of 7 to 9 pigs of each group were compared among each other. At DPC 0 unstimulated PBMCs were also evaluated to determine the frequency of different $\mathrm{T}$ cell subsets by flow cytometry analysis.

At DPC6 PBMCs of pigs were restimulated with SwIV H1N2 and H1N1 at MOI 0.1 and subjected to cell proliferation as described above. The supernatant harvested from $72 \mathrm{hrs}$ of restimulated PBMCs culture were analyzed for IFN- $\gamma$ by ELISA, and cells were subjected to 
immunophenotyping and analyzed by flow cytometry to determine the frequency of activated $\mathrm{T}$ cell subsets as described previously [27]. Briefly, PBMCs were blocked with 2\% pig serum and surface-labeled with pig lymphocyte specific purified, fluorochrome or biotin conjugated mAbs followed by treatment with fluorochrome labeled anti-mouse isotype specific or streptavidin antibody. For intracellular IFN $\gamma$ staining, GolgiPlugTM (BD Biosciences, CA) and Brefeldin A (Sigma, MO) were added during the last 6 hrs of incubation of PBMCs treated with or without indicated stimulants. The surface immunostained cells were fixed with $1 \%$ paraformaldehyde and permeabilized with cell-permeabilization buffer (85.9\% deionized water, 11\% PBS without $\mathrm{Ca}_{2}{ }^{+}$or $\mathrm{Mg}_{2}{ }^{+}, 3 \%$ formaldehyde solution, and $0.1 \%$ saponin) overnight at $4{ }^{\circ} \mathrm{C}$. Cells were washed and immunostained using fluorochrome-conjugated anti-pig IFN $\gamma$ or its isotype control $\mathrm{mAb}$ (BD Biosciences, $\mathrm{CA}$ ) in $0.1 \%$ saponin containing fluorescence-activated cell-sorting (FACS) buffer. Immunostained cells were acquired using the flow cytometer BD Aria II (BD Biosciences, CA) and analyzed using the FlowJo software (Tree Star, OR). All specific cell population frequencies were presented as the percent of total $\mathrm{CD}^{+} / \mathrm{CD}^{-}$lymphocytes. To define CTLs (CD8 $\alpha \beta^{+} \mathrm{T}$ cells), cells were gated first for $\mathrm{CD} 8 \alpha$ marker followed by $\mathrm{CD} 8 \beta$ and $\mathrm{T}$ cells double positive were considered as CTLs. Antibodies used in the flow cytometry were: antiporcine CD3 (Southernbiotech, AL), CD4 $\alpha$ (Southernbiotech, AL), CD8 $\alpha$ (Southernbiotech, $\mathrm{AL}$ ), CD8ß (BD Biosciences, CA) and $\delta$-chain (BD Pharmingen, CA).

\subsection{Virus titration}

Serial 10-fold dilutions of test samples in serum-free DMEM containing TPCK-trypsin (1 $\mu \mathrm{g} / \mathrm{ml}$ ) in quadruplicates were transferred to monolayer of MDCK cells cultured overnight in 96 well cell culture plates. Plates were incubated for $48 \mathrm{hrs}$ at $37^{\circ} \mathrm{C}$ in a $5 \% \mathrm{CO}_{2}$ incubator and fixed using $80 \%$ acetone in water and immunostained using IAV nucleoprotein specific primary 
antibody (\#M058, CalBioreagents, CA) followed by Alexa Fluor 488 conjugated goat antimouse $\mathrm{IgG}(\mathrm{H}+\mathrm{L})$ antibody (Life technologies, OR). Immunofluorescence was recorded using fluorescent microscope (Olympus, NY) and infectious virus titer was calculated using Reed and Muench method [37].

\subsection{Antibody titration}

Hemagglutination inhibition (HI) titers and specific antibody levels were determined as described previously [27]. Briefly, HA units of SwIV H1N1 was first determined and the virus stock was diluted to get $8 \mathrm{HA}$ units in $50 \mu \mathrm{l}$ volume and used in a standard HI assay. Plasma and BAL fluid samples were incubated at $56^{\circ} \mathrm{C}$ for $30 \mathrm{~min}$ to inactivate innate complement activity. The starting dilution of plasma and BAL fluid for HI assay was 1:2. SwIV specific IgG and IgA antibodies in nasal swab, BAL fluid, lung lysate and plasma samples were determined by ELISA. Briefly, flat bottom high binding 96 well plates (Greiner bio-one, NC) were coated with semipurified pretitrated SwIV H1N1 or H1N2 antigens $(5 \mu \mathrm{g} / \mathrm{ml})$ and incubated at $4^{0} \mathrm{C}$ overnight. Plates were blocked with 5\% skim milk in PBST for $2 \mathrm{hrs}$ at RT and washed three times with PBST. Samples diluted in $2.5 \%$ skim milk were added $50 \mu 1 /$ well in duplicate and incubated at RT for 2 hrs. After three washes goat anti-pig IgA conjugated with HRP (Bethyl Laboratories Inc., TX) or goat anti-pig IgG $(\gamma)$ conjugated with HRP (KPL, MD) was added at $50 \mu 1 /$ well (both the antibodies were diluted at 1:1000 in 2.5\% skim milk in PBST) and incubated at RT for $2 \mathrm{hrs}$. The Ag-Ab reaction was developed calorimetrically by adding 1:1 mixture of peroxidase substrate solution B and TMB peroxidase substrate (KPL, MD) $50 \mu 1 /$ well. The reaction was stopped after 10-20 min by adding $1 \mathrm{M}$ phosphoric acid (50 $\mu \mathrm{l} /$ well). Optical density (OD) was measured at $450 \mathrm{~nm}$ using the Spectramax microplate reader, and corrected OD value was obtained after subtracting blank OD from mean OD of different treatment groups. Virus 
neutralization titer (VNT) in BAL fluid was determined using the procedures described previously [27].

\subsection{Histopathology and Immunohistochemistry analyses}

Five $\mu \mathrm{m}$ sections of apical, cardiac and diaphragmatic lung lobes of pigs were stained with hematoxylin and eosin and examined microscopically for histopathological changes as described previously [34]. Peri-bronchial and perivascular accumulation of mononuclear inflammatory cells (MNCs) as well as bronchial exudates composed of dead sloughed epithelial cells and MNCs were scored as follows: 0 , no change from normal; 0.5 , changes present but too mild; 1 , minimal changes from normal; 2, moderate changes from normal; and 3, marked changes from normal. Final lung pathology score for each pig was determined by taking the average of scores from the three lung lobes and the group averages were compared.

SwIV specific antigens were detected in the lungs by IHC method as described previously with a few modifications [36, 38], and were henceforth called as the antigenic mass. Briefly, $5 \mu \mathrm{m}$ tissue sections were deparaffinized and hydrated in Dulbecco's PBS (D-PBS) and incubated in $0.05 \%$ sodium borohydride solution for $10 \mathrm{~min}$ to break aldehyde bonds, washed twice and incubated in Protease VII (diluted 1:6.5 with D-PBS) for 30 min at RT for antigen retrieval. Slides were washed thrice and quenched in $3 \% \mathrm{H}_{2} \mathrm{O}_{2}$ solution for $5 \mathrm{~min}$, followed by three washes slides were blocked by incubating with $4 \%$ normal horse serum for $20 \mathrm{~min}$ at RT. Further, slides were incubated with SwIV nucleoprotein specific antibody (\#MO58, CalBioreagents, CA) for 60 min at RT, washed thrice, and incubated with biotinylated secondary antibody for 60 min at RT. To detect positive signals, slides were incubated in VECTASTAIN elite ABC reagent (\#PK-7100, Vector Lab., CA) followed by treatment with ImmPACT ${ }^{\mathrm{TM}}$ DAB Substrate (\#SK-4105, Vector Lab., CA) as per manufacturer's instructions. The slides were 
rinsed in tap water, counterstained with hematoxylin, rinsed well in tap water, dehydrated and mounted. Positive IHC signals on bronchial epithelium of apical, cardiac and diaphragmatic lung lobes were scored according to the following criteria: 0 , no changes comparable to mock control - normal; 0.5, suggestive but not definite; 1 , minimal changes from normal; 2 , moderate changes from normal; and 3, marked changes from normal. IHC score for each pig was determined by taking the average of scores from all three lung lobes and treatment pig group averages were compared. Microscopic and IHC slides were read by a board certificated veterinary pathologist who was blinded to the experimental design and SwIV infection status.

\subsection{Ethics Statement}

This study was carried out in strict accordance with the recommendations by the Public Health Service Policy, USDA Regulations, National Research Council's Guide for the Care and Use of Laboratory Animals and the Federation of Animal Science Societies' Guide for the Care and Use of Agricultural Animals in Agricultural Research and Teaching. All the pigs were maintained, samples collected and euthanized, and all efforts were made to minimize the suffering of pigs as per the approved institutional, state and federal regulations and policies regarding animal care and use at The Ohio State University on the Ethics for Animal Experiments (Protocol Number: 2014A00000099).

\subsection{Statistical analysis}

Data were presented as mean \pm standard error of mean (SEM) of 7-9 pigs. For HI and VN titers data were presented as geometric mean \pm SEM of 7-9 pigs. For virus titer, titers of $10^{0}$ were used for less than $10^{1}$ values; transformed to a $\log _{10}$ scale and analyzed [36]. In each assay, the differences of means among the groups were determined by one-way analysis of variance 
(ANOVA) followed by Tukey's post-hoc comparison test in GraphPad Prism 5 (GraphPad Software, Inc., CA). A p-value less than 0.05 was considered statistically significant.

\section{Results}

\subsection{In vitro characterization of PLGA-KAg NPS}

The encapsulation efficiency of KAg in PLGA-NPs was 57\%. This result was comparable to our previous results of PLGA encapsulation of peptides as well as inactivated PRRSV with 50-60\% encapsulation efficiency [27, 39]. Morphology of PLGA-KAg was determined using scanning electron microscope and size distribution was calculated by analyzing 200 NPs using the ImageJ software. PLGA-KAg were spherical in shape (Fig. 1A) with the mean diameter of $313 \mathrm{~nm}$ and standard deviation of $105 \mathrm{~nm}$. Most of the NPs were in the size range of 200-300 nm diameter. For efficient uptake of NPs by APCs and M cells at mucosal surface, the ideal particle size is $\leq 500 \mathrm{~nm}[22,24]$, and approximately 95\% PLGA-KAg particles were $\leq 500 \mathrm{~nm}$ (Fig. 1B). The charge of NPs was determined by a Quasi elastic light scattering experiment and found to be $-18 \pm 0.56 \mathrm{mV}$. The particle size and charge were comparable to our previous PLGA NPs [26, 27, 39]. During viral antigen encapsulation in NPs a fraction of the antigen is always associated on the surface of particles, which gets released immediately ( $\leq 30 \mathrm{~min})$ after reconstitution in physiological buffers like PBS and it is called burst release [40]. We observed burst release of $22 \%$, and after $24 \mathrm{hrs} 27 \%$ of encapsulated cumulative quantity of KAg was released. Further, slow and sustained release of antigen was observed over a period of 4 week and the total cumulative release of KAg was approximately 50\% after one month (Fig. 1C). This result was comparable to our earlier PLGA-NPs preparations encapsulated with IAV peptides and inactivated PRRSV [26, 27]. 


\subsection{PLGA-KAg NPs induced maturation of antigen presenting cells in vitro}

M $\phi s$ and DCs are the major APCs. Like in other species, porcine BAL cells contain greater than $90 \% \mathrm{M} \phi \mathrm{s}$, and hence BAL cells were not further purified and used as a source of M $\phi$ s along with MoDCs to investigate the adjuvant properties of PLGA-KAg in vitro. M $\phi$ s and MoDCs were treated with medium only, soluble KAg $(2 \mu \mathrm{g} / \mathrm{ml})$ or PLGA-KAg (containing 2 $\mu \mathrm{g} / \mathrm{ml}$ of $\mathrm{KAg}$ ) and analyzed for the expression of APCs maturation marker, costimulatory molecules CD80/86. MoDCs were also treated with control empty PLGA-NPs at the same w/v concentration present in the PLGA-KAg to determine the adjuvant role of PLGA-NPs alone. Our results showed that in PLGA-KAg treated MoDCs expression of CD80/86 was significantly higher (40\%) compared to medium control, KAg alone and empty PLGA-NPs treatment $(<25 \%)$ (Fig. 1D). Similarly, in M $\phi s$ also expression of CD80/86 was significantly higher in PLGA-KAg treated compared to medium control. The percentage of CD80/86 expression in PLGA-KAg treated M $\phi s(14 \%)$ was higher than KAg only treatment (8.5\%) (Fig. 1E). This trend was similar when M $\phi s$ and MoDCs were treated with higher concentration of the KAg $(20 \mu \mathrm{g} / \mathrm{ml})$ (data not shown). Furthermore, empty PLGA-NPs and KAg only also induced slightly increased CD80/86 expression in MoDCs (26\%) compared to medium control (21\%) (Fig.1D). PLGA-KAg

particles compared to control empty PLGA-NPs induced significantly higher adjuvant effects on treated MoDCs, suggesting the additive adjuvant effects of KAg when encapsulated in NPs.

\subsection{PLGA-KAg NPs vaccine induced antigen specific cellular response in pigs pre-challenge}

Stimulation index (SI) of PLGA-KAg vaccinated pigs was significantly higher compared to mock and KAg vaccinated animals stimulated with either the SwIV H1N2 (Fig. 2A) or H1N1 
(Fig. 2B), indicating that PLGA-KAg vaccine recipient pigs had immune cells sensitized even against the heterologous SwIV. Flow cytometry analysis of PBMCs at DPV 35 (without any SwIV stimulation) demonstrated that PLGA-KAg vaccination induced generation of significantly higher frequency of $\mathrm{CD} 3^{+} \mathrm{CD} 4^{+} \mathrm{CD} 8 \alpha^{+} \mathrm{T}$ cells (Fig. 2C), which are called as activated/memory $\mathrm{T}$ helper cells in pigs [41], and aslo CTLs $\left(\mathrm{CD} 3^{+} \mathrm{CD} 4^{+} \mathrm{CD} 8 \alpha \beta^{+}\right)$compared to KAg received pig group (Fig. 2D). We also observed significantly increased frequency of $\gamma \delta \mathrm{T}$ cells in PLGA-KAg vaccinated pigs compared to KAg group (Fig. 2E).

Significantly higher HI titer was observed both in KAg and PLGA-KAg vaccinated pig groups compared to mock group. However, we did not find any statistical difference in HI titer between KAg and PLGA-KAg received groups (Table 4). Interestingly, plasma IgG antibody response was significantly higher in KAg vaccinated pigs compared to PLGA-KAg recipients (Table 4). In both KAg and PLGA-KAg vaccinated pig groups, HI titers against the vaccine virus (SwIV H1N2) at DPV 21 were low (Table 4), and the virus specific IgG response was also low (data not shown). Also we did not observe any difference in IgA antibody titers in nasal swab samples collected at DPV 35/DPC 0 among different vaccine groups (data not shown). Overall, our pre-challenge data demonstrated that PLGA encapsulation of inactivated SwIV delivered intranasally in pigs induced a strong cell-mediated with moderate to weak humoral immune response.

3.4 PLGA-KAg NPs vaccine rescued pigs from clinical flu symptoms, lung pathology and viral load in the lungs post-challenge

Pigs were vaccinated intranasally using the multidose aerosoal device which provides fine mist particles (Fig. 3). In SwIV H1N1 challenged, mock and KAg vaccinated pigs we 
observed fever with the mean rectal temperature until DPC 4 remained $>104^{0} \mathrm{~F}$, and also most of those pigs were anorexic and lethargic during those four days post-challenge (Table 2). While PLGA-KAg vaccinated pigs had fever only until DPC 1 (Table 2) with mild flu symptoms, and from DPC 2 onwards they were apparently normal and comparable to mock pigs.

On the day of necropsy (DPC 6) lungs were examined and scored for percentage consolidation due to influenza infection. The gross lung lesion scores in PLGA-KAg vaccinated pigs (mean=12.1) was lower than KAg group (mean=20.8) and significantly lower than mockinfected animals (mean=23.9) (Table 3). The representative lung pictures showing gross lung lesions are shown (Fig. 4A). Microscopic lung lesions showed lower percentage of inflammatory cell infiltration around the bronchioles and bronchial epithelium of PLGA-KAg vaccinated pigs, suggesting the vaccine induced protection in the lungs of heterologous SwIV challenged pigs (Fig. 4B; Table 3).

The antigenic mass in PLGA-KAg vaccinated and virus challenged pigs was significantly lower than mock as well as KAg vaccinated and virus challenged animals (Table 3). The IHC scores and H\&E results revealed that the lungs of PLGA-KAg vaccinated pigs were least affected by the virulent heterologous challenge virus, and they were comparable to mock uninfected pigs at DPC 6 in terms of influenza antigenic mass. The representative IHC pictures from each of respective pig groups are shown (Fig. 4C).

We also determined the infectious SwIV H1N1 virus titer in the BAL fluid at DPC 6, and all the mock vaccinated and virus challegned pigs were found positive for virus (8/8), while 5 of $8 \mathrm{KAg}$ and only 2 of 9 PLGA-KAg vaccinated pigs were positive for the SwIV H1N1. Though the average challenge SwIV titers of 8 to 9 pigs of both $\mathrm{KAg}\left(10^{2.4} \mathrm{TCID}_{50} / \mathrm{ml}\right)$ and PLGA-KAg $\left(10^{0.8} \mathrm{TCID}_{50} / \mathrm{ml}\right)$ vaccinated pgis were significantly reduced in the BAL fluid compared to 
mock-infected $\left(10^{5.3} \mathrm{TCID}_{50} / \mathrm{ml}\right)$ animals. PLGA encapsulation of SwIV KAg led to a substantial reduction (40-fold) in the infectious lung virus titer compared to soluble KAg vaccination in pigs (Table 3). Further, we also tested virus shedding in nasal swabs at DPC 4 and 6, but surprisingly unlike in the BAL fluid, nasal viral shedding at DPC 4 was comparable in all the vaccinated and mock-infected pig groups; and by DPC 6 it was equally reduced across all the groups. Overall, there was no difference in the nasal virus shedding between the KAg and PLGA-KAg vaccine recipient pigs (Table 3). Our data suggested that intranasal delivery of PLGA encapsulated SwIV KAg provided clinical protection against a heterologous virus challenge and reduced the lung pathology and replicating infectious virus load in the lungs of pigs.

\subsection{PLGA-KAg vaccination induced enhanced IFN $\gamma$ secretion and activated recall $T$ cell} response in virus challenged pigs

At pre-challenge DPC 0 augmented cellular immune response in PLGA-KAg vaccinated pigs in PBMCs was detected (Fig. 2), therefore we performed a similar analysis post-challenge at DPC 6 in pig groups. To reveal the recall cellular response, PBMCs were stimulated ex vivo with either the vaccine $(\mathrm{H} 1 \mathrm{~N} 2)$ or challenge $(\mathrm{H} 1 \mathrm{~N} 1) \mathrm{SwIV}$ and analyzed for the activated (IFN $\left.\gamma^{+}\right) \mathrm{T}$ lymphocyte subsets. A representative graph showing gating pattern followed for analysis of different $\mathrm{T}$ cell subsets in pigs by flow cytometry is shown (Fig. 5).

Total IFN $\gamma$ producing T cells $\left(\mathrm{CD}^{+}\right)$were significantly higher in PLGA-KAg received pig group compared to KAg received animals stimulated with both vaccine and challenge viruses (Fig. 6A). $\mathrm{CD}^{-} \mathrm{IFN}^{+}$cells were significantly higher in KAg than PLGA-KAg vaccinated pig groups, irrespective of virus restimulation conditions (Fig. 6B). $\mathrm{CD} 3{ }^{+} \mathrm{CD} 4^{+} \mathrm{CD} 8 \alpha^{+} \mathrm{IFN} \gamma^{+}$(activated T- 
helper/memory) cells were significantly higher in mock-challenge pig group in response to $e x$ vivo stimulation with challenge virus, but not with vaccine virus, suggesting the activation of memory cells in pigs (Fig. $6 \mathrm{C}$ ). $\mathrm{CD}^{+} \mathrm{CD}^{+} \mathrm{CD} 8 \alpha^{-} \mathrm{IFN} \gamma^{+}$(activated T-helper) cells were significantly higher in PLGA-KAg vaccinated pig group compared to both mock-challenge and KAg received groups cells stimulated with challenge virus, but significantly enhanced compared to mock-challenge group on stimulation with vaccine virus (Fig. 6D). IFN $\gamma$ producing $\mathrm{CD}^{+} \mathrm{CD} 4 \mathrm{CD} 8 \alpha \beta^{+} \mathrm{IFN} \gamma^{+}$(activated CTLs) cells were significantly augmented in PLGA-KAg vaccinated pig group compared to both mock-challenge and KAg vaccinated animals stimulated with both vaccine and challenge viruses (Fig. 6E). Consistent with increased CD3 IFN $\gamma^{+}$cell subset response observed in KAg vaccinated pig group, IFN $\gamma$ producing NK cell subsets (CD3$\mathrm{CD} 4{ }^{-} \mathrm{CD} 8 \mathrm{a}^{+} \mathrm{IFN} \gamma^{+}$) were also significantly higher compared to mock challenged animals (Fig. 6F). Consistent with the flow cytometry data, IFN $\gamma$ secretion by restimulated PBMCs was also significantly higher in PLGA-KAg vaccinated and virus challenged pigs compared to both mockchallenge and KAg vaccinated animals (Fig. 7A). Further, IFN $\gamma$ secretion into the cell culture supernatant was significantly higher in H1N2 stimulated PBMCs of PLGA-KAg vaccinated pig group compared to unstimulated control cells (CC) (Fig. 7B), indicating the presence of antigen specific recall Th1 response. Overall, our lymphocyte response analysis data both at pre- and post-challenge in PLGA-KAg vaccinated pigs suggested induction of a strong cellular immune response.

3.6 KAg compared to PLGA-KAg vaccination induced higher IgA and IgG responses, but HI and virus neutralization titers were comparable 
Intranasal delivery of vaccine is thought to induce strong local mucosal immunity.

Therefore, we determined IgA response in nasal swab, BAL fluid and lung lysate samples, and suprisingly found significantly higher response against SwIV H1N1 in KAg compared to PLGAKAg vaccinated and virus challenged pigs (Table 4). We also checked specific IgG antibody levels against SwIV H1N1 and did not find any difference in the plasma among all the experimental pig groups (Table 4), but the levels were significantly higher in BAL fluid of KAg vaccinated pigs (Table 4). IgA and IgG antibody response against vaccine virus (SwIV H1N2) also had a similar higher trend in KAg rather than PLGA-KAg vaccinated pigs (data not shown). We observed absence of statistical difference in HI titer against SwIV H1N1 in the BAL fluid and plasma between KAg and PLGA-KAg vaccinated pig groups (Table 4). Similarly, there was no difference in $\mathrm{HI}$ titer against SwIV H1N2 in plasma, but HI titer in BAL fluid against SwIV H1N2 was significantly higher in PLGA-KAg compared to KAg vaccinated pig groups (data not shown). Surprisingly, irrespective of significantly higher $\operatorname{IgG}$ and $\operatorname{Ig} \mathrm{A}$ antibody response detected in KAg vaccinated pigs, the virus neutralization titers were comparable to that of PLGA-KAg vaccinated animals (Table 4). Overall, our cellular and humoral immune response data suggested that intranasal vaccination with both the KAg and PLGA-KAg failed to induce strong $\mathrm{HI}$ and virus neutralizing antibody responses locally at the lungs as well as systemically in blood of pigs. However, PLGA encapsulation of SwIV KAg elicited strong cross-protective cellmediated immunity.

\section{Discussion}

PLGA polymer is extensively used in drug and vaccine delivery studies due to its nontoxic, biodegradable and biocompatible properties [18]. PLGA based candidate viral vaccines 
delivered intranasally in rodent models in the absence of any adjuvant have shown great promise against hepatitis B, equine encephalitis, influenza and parainfluenza by inducing strong cellular and humoral immune responses [42-47]. In dairy calves immunized intranasally with PLGA encapsulated bovine parainfluenza virus, enhanced virus specific antibody response was observed [48]. Our earlier studies in pigs indicated that intranasal delivery of PLGA-NPs based inactivated PRRSV induced enhanced cross-protective both cellular and humoral immune responses only when coadministered with a potent adjuvant $[26,38,49]$. In a recent study in pigs, vaccinated intranasally with PLGA-NPs encapsulated conserved IAV pooled T and B cell peptides cocktail, peptide specific cellular (but not humoral) immune response was upregulated, and the pigs were rescued from clinical flu and cleared the infectious replicating challenge virus from the lungs better than the control animals [27]. In this study, our goal was to improve virus specific both humoral and cell-mediated immune responses and augment cross-protective efficacy of PLGA-NPs delivered inactivated SwIV, which likely provides greater number of potential B and T cell epitopes to pig immune system compared to selected few peptides used ealier [27]. Our results in pigs indicated that PLGA-NPs delivered inactivated SwIV failed to augment humoral response in spite of significantly boosting the cell-medited response, suggesting that likely the important cytokines and chemokines required for activiaton and interaction of B cells with T-helper cells were not secreted. Because when PLGA-NPs delivered inactivated PRRSV coadministered with a potent mucosal adjuvant intranasally boosted both humoral and cell-mediated responses $[26,49]$. Thus, it is unlikely that B cell epitopes were damaged during the vaccine formulation process or they were masked by the NPs when phagocytosed by APCs. 
Particulate delivery of antigens in NPs enhances its uptake by APCs [50, 51]. PLGA encapsulated PRRSV in comparison to soluble antigen was efficiently uptaken by $M \phi s$ [26]. Size of the NPs plays a critical role in rate of uptake and fate of antigen in APCs, wherein $\leq 500 \mathrm{~nm}$ size NPs are readily uptaken and processed by APCs [22-24, 52, 53]. Consistent with that PLGA-KAg particles were around $300 \mathrm{~nm}$ and found efficiently uptaken by pig APCs. Sustained slow release of vaccine antigens when delivered by parenteral route provides long-lasting immune response, avoid the risk of tolerance and need of additional boosts; and also essential for expansion of antigen specific CD4 and CD8 T cells and differentiation of memory T cells [54, 55]. But when particulate NPs entrapped vaccine is delivered intranasal the expected benefit is protection of entrapped antigens from proteolytic degradation at mucosal surfaces and facilitation of its uptake by immune cells present at the mucosal sites, which is critical for induction of strong mucosal immunity. PLGA-KAg had approximately 50\% entrapped vaccine antigens left even after 4 weeks of its suspension in phsyiological saline conditions in vitro, suggesting that the prolonged availability of PLGA-KAg particles facilitated uptake by APCs present at the mucosal surfaces. This nature of PLGA-KAg was comparable to PLGA-NPs encapsulated PRRSV and influenza viral peptides [26, 27].

PLGA-NPs also possess inherent adjuvant properties by inducing maturation of APCs $[56,57]$. PLGA-NPs encapsulated PRRSV was shown to induce increased expression of CD80/86 on treated M $\phi \mathrm{s}$ [38]. Similarly, PLGA based particles were shown to induce maturation of human MoDCs and murine bone marrow derived DCs [58, 59]. Consistent with that, PLGA$\mathrm{KAg}$ also induced expression of CD80/86 on treated pig M $\phi s$ and DCs. Interestingly, synergistic adjuvant effect was observed in PLGA-KAg treated DCs compared to empty PLGA-NPs treatment, suggesting the innate adjuvant effects of inactivated KAg when presented in NPs. DCs 
pulsed with PLGA-NPs were shown to increase CD86 expression at modest level, which was synergistically increased when immunogen monophosphoryl lipid A was encapsulated in PLGANPs [60]. Overall, PLGA based inactivated SwIV NPs vaccine had desirable properties of an ideal particulate vaccine.

Cell-mediated immune response is vital for clearing intracellular pathogens, and antigen presentation by MHC class I pathway mediates CTLs response [61]. Although inactivated soluble antigens are not processed through MHC class I molecuels and elicit poor cellular response, PLGA-NP delivery system overcome that lacunae by facilitating cross-presentation of encapsulated soluble antigens by APCs through endolysosomal escape mechanism [62-64], mediated through rapid reversal of NP surface charge from anionic to cationic inside the endolysosomal compartment [65]. In this study, though we did not test such a mechanism operating in the pig system, the augmented $\mathrm{T}$ cell response in both pre- and post-challenged PLGA-KAg vaccinated pigs suggested operation of such a mechanism. Unlike in mice and humans, in pigs some of the T cell subsets are defined slightly different[66-68], $\mathrm{CD}^{+} \mathrm{CD} 4^{+} \mathrm{CD} 8 \alpha^{+} \mathrm{T}$ cells are regarded as activated/memory $\mathrm{T}$-helper cells, and $\mathrm{CD}^{+} \mathrm{CD} 4^{+} \mathrm{CD} 8 \alpha^{-}$cells as naïve T-helper cells [69]. We observed enhanced frequency of activated/memory $\mathrm{T}$ helper cells in PLGA-KAg vaccinated pre-challenge pigs. PLGA-KAg vaccinated pig lymphocytes were found to be primed against influenza virus antigens, indicated by increased antigen specific lymphocyte proliferation. Cells bearing $\mathrm{CD} 3^{+} \mathrm{CD} 4{ }^{-} \mathrm{CD} 8 \alpha \beta^{+}$markers are CTLs which help in complete clearance of virus infected cells in pigs [67]. In PLGA-KAg vaccinated pigs at DPC 6, frequency of activated CTLs and naïve T-helper cells were upreguatled, but not memory T-helper cells . We do not know why upreguatled levels of memory T-helper cells observed in pigs pre-challenge were not maintained at higher frequency post- 
challenge in PLGA-KAg vaccinated pigs. However, our results are consistent with earlier studies wherein upregulation of CTLs mediated through PLGA delivery system was associated with augmented immunity [70-72].

$\gamma \delta$ T cells are innate immune cells which play a vital role in mediating antiviral immune response [73], and in pigs they are relatively abundant compared to in other species of animals [74]. PLGA-KAg vaccinated pigs showed higher frequency of $\gamma \delta$ T cells which also would have contributed in induction of protective immune function against influenza. PLGA-KAg elicited protective efficacy against a virulent heterologous challenge virus, indicated by the absence of clinical flu symptoms, reduced gross and microscopic lung pathology and challenge viral clearance from the lungs. Overall, effector and memory recall T cell responses in PLGA-KAg vaccinated pigs were stronger and robust, particuarly CTLs response compared to PLGA encapsulated conserved peptides cocktail vaccinated pigs [27]; and this was comparable to inactivated PRRSV encapsulated PLGA vaccine coadministered with a potent adjuvant [26, 49].

For prevention of influenza viral transmission and induction of protection, wherein the virus primarily infects respiratory tract epithelial cells, induction of strong mucosal antibody response in the upper respiratory tract is critical, and vaccine delivery through nostrils have that potential $[75,76]$. In our study, specific HI titer in plasma was not increased in PLGA-KAg vaccinated pigs compared to KAg group. Surprisingly, though plasma IgG and BAL fluid IgA and $\mathrm{IgG}$ responses were significantly higher in KAg compared to PLGA-KAg vaccinated pigs at both pre-and post-challenge, but the virus neutralization titer against the challenge virus in BAL fluid was comparable in KAg and PLGA-KAg vaccinated pigs. Clearance of replicating virus in $40 \%$ of pig lungs in KAg vaccinated compared to mock-infected pigs appears to be contributed by antibodies and increased innate NK cells, but the clinical disease and lung pathology 
remained comparable to mock-challenged animals. Therefore, induction of strong cell-mediated immune response (CTLs) in inactivated SwIV vaccinated pigs is essential to limit the severity of influenza in pigs. Hence innovative vaccination strategies should explore T cell immunity to provide broad protective response $[77,78]$. Activated lymphocytes produce IFN- $\gamma$, which play a significant role in influenza viral clearance [27, 79]. Although PLGA-KAg vaccination induced less of $\operatorname{IgA}$ and $\mathrm{IgG}$ antibody response than KAg at mucosal and systemic sites, the HI and VN titers were comparable. However, the nasal viral shedding was not reduced and found comparable in all three virus-challenged groups, suggesting that mucosal antibody response was weak in PLGA-KAg vaccinated pigs which needs to be boosted by making important modifcations in the vaccine formulation.

The particulate vaccines trials to advance the potential of nanotechnology based approach demand the evaluation of a candidate vaccines in multiple animal models, including in pig before choosing the right model for translational studies to revolutionize vaccine development against highly demanding respiratory infections like influenza in humans [80]. In mice using a welldefined and highly conserved IAV-derived CTLs peptides encapsulated in PLGA microspheres induction of strong CTLs response and complete protection against a viral challengewas achieved [81]. But our data in pigs showed that induction of strong CTLs response by using PLGA-KAg vaccine has helped to reduce the clinical flu symptoms, substantially cleared the challenged heterologous virus from the lungs, but failed to reduce the nasal viral shedding; suggesting the need of concurrent increase in secretion of mucosal antibody response along with induction of strong CTLs response through modifying the PLGA-KAg formulation. 


\section{Conclusion}

In conclusion, we demonstrated that intranasal delivery of PLGA based inactivated SwIV vaccine induced strong CTL response resulting in protection from a virulent heterologous influenza virus induced clinical disease, reduced the lung pathology and substantially cleared the virulent zoonotic heterologous challenge virus from the lungs of pigs. Since the strong CTL response is capable of providing heterosubtypic immunity in influenza infections in mice, PLGA based vaccination approach forms an ideal platform to use the pig model for translation of particulate candidate flu vaccine to effectively control flu pandemics in humans. Our future studies will focus on enhancing mucosal IgA antibody response to produce balanced Th1/Th2 immunity by incorporating Th2 based adjuvants in our candidate PLGA vaccine formulation to further improve the vaccine efficacy.

\section{Acknowledgements}

We are thankful to Dr. Juliette Hanson and Megan Strother who provided help in animal studies. This work was supported by Agriculture and Food Research Initiative Competitive Grant no. 2013-67015-20476 from the USDA-NIFA and Nanovaccine Research Initiative, Iowa state University. Dr. Artur Summerfield (Institute of Virology and Immunology, Mittelhäusern, Switzerland) has shared his protocol for our pig dendritic cell study. Salaries and research support were provided by state and federal funds appropriated to OARDC, The Ohio State University. 


\section{References}

[1] A. Vincent, L. Awada, I. Brown, H. Chen, F. Claes, G. Dauphin, R. Donis, M. Culhane, K. Hamilton, N. Lewis, E. Mumford, T. Nguyen, S. Parchariyanon, J. Pasick, G. Pavade, A. Pereda, M. Peiris, T. Saito, S. Swenson, K. Van Reeth, R. Webby, F. Wong, J. Ciacci-Zanella, Review of Influenza A Virus in Swine Worldwide: A Call for Increased Surveillance and Research, Zoonoses and Public Health, 61 (2014) 4-17.

[2] T. Ito, J.N. Couceiro, S. Kelm, L.G. Baum, S. Krauss, M.R. Castrucci, I. Donatelli, H. Kida, J.C. Paulson, R.G. Webster, Y. Kawaoka, Molecular basis for the generation in pigs of influenza A viruses with pandemic potential, J Virol, 72 (1998) 7367-7373.

[3] H.C. Dykhuis, T. Painter, T. Fangman, H. D, Assessing production parameters and economic impact of swine influenza, PRRS and Mycoplasma hyopneimoniae on finishing pigs in a large production system in: Proceedings of AASV Annual Meeting, 2012, pp. 75-76.

[4] B.H. Janke, Clinicopathological features of Swine influenza, Curr Top Microbiol Immunol, 370 (2013) 69-83.

[5] WHO, Roos, Robert (8 August 2011). "Study puts global 2009 H1N1 infection rate at $11 \%$ to 21\%". CIDRAP. Retrieved 10 August 2011., (2011).

[6] F.S. Dawood, A.D. Iuliano, C. Reed, M.I. Meltzer, D.K. Shay, P.Y. Cheng, D. Bandaranayake, R.F. Breiman, W.A. Brooks, P. Buchy, D.R. Feikin, K.B. Fowler, A. Gordon, N.T. Hien, P. Horby, Q.S. Huang, M.A. Katz, A. Krishnan, R. Lal, J.M. Montgomery, K. Molbak, R. Pebody, A.M. Presanis, H. Razuri, A. Steens, Y.O. Tinoco, J. Wallinga, H. Yu, S. Vong, J. Bresee, M.A. Widdowson, Estimated global mortality associated with the first 12 months of 2009 pandemic influenza A H1N1 virus circulation: a modelling study, Lancet Infect Dis, 12 (2012) 687-695.

[7] CDC, "First Global Estimates of 2009 H1N1 Pandemic Mortality Released by CDC-Led Collaboration". Centers for Disease Control and Prevention (CDC). 25 June 2012. Retrieved 3 July 2012., (2009).

[8] WHO, Pandemic (H1N1) 2009 - update 100". Disease Outbreak News [World Health Organization (WHO)]. 14 May 2010. Archived from the original on 18 May 2010. Retrieved 14 May 2010., (2010).

[9] H.N. WHO, "H1N1 Still A Pandemic, Says WHO". redOrbit. Retrieved 10 August 2010., (2010).

[10] L.C. Lambert, A.S. Fauci, Influenza vaccines for the future., N Engl J Med, 363 (2010) 2036-2044.

[11] W.H. Organization, Influenza (seasonal) fact sheet, in, 2014.

[12] A.H. Ellebedy, R.J. Webby, Influenza vaccines, Vaccine, 27 Suppl 4 (2009) D65-68.

[13] M. Savic, J.L. Dembinski, Y. Kim, G. Tunheim, R.J. Cox, F. Oftung, B. Peters, S. Mjaaland, Epitope specific T-cell responses against influenza A in a healthy population, Immunology, 147 (2016) 165-177.

[14] P.C. Gauger, A.L. Vincent, C.L. Loving, K.M. Lager, B.H. Janke, M.E. Kehrli, Jr., J.A. Roth, Enhanced pneumonia and disease in pigs vaccinated with an inactivated human-like (deltacluster) H1N2 vaccine and challenged with pandemic 2009 H1N1 influenza virus, Vaccine, 29 (2011) 2712-2719.

[15] P. Kitikoon, A.L. Vincent, B.H. Janke, B. Erickson, E.L. Strait, S. Yu, M.R. Gramer, E.L. Thacker, Swine influenza matrix 2 (M2) protein contributes to protection against infection with different H1 swine influenza virus (SIV) isolates, Vaccine, 28 (2009) 523-531. 
[16] A.L. Vincent, K.M. Lager, B.H. Janke, M.R. Gramer, J.A. Richt, Failure of protection and enhanced pneumonia with a US H1N2 swine influenza virus in pigs vaccinated with an inactivated classical swine H1N1 vaccine, Vet Microbiol, 126 (2008) 310-323.

[17] H.K. Makadia, S.J. Siegel, Poly Lactic-co-Glycolic Acid (PLGA) as Biodegradable Controlled Drug Delivery Carrier, Polymers (Basel), 3 (2011) 1377-1397.

[18] F. Danhier, E. Ansorena, J.M. Silva, R. Coco, A. Le Breton, V. Preat, PLGA-based nanoparticles: an overview of biomedical applications, J Control Release, 161 (2012) 505-522.

[19] A. Mahapatro, D.K. Singh, Biodegradable nanoparticles are excellent vehicle for site directed in-vivo delivery of drugs and vaccines, Journal of Nanobiotechnology, 9 (2011) 1-11.

[20] D.R. Getts, L.D. Shea, S.D. Miller, N.J. King, Harnessing nanoparticles for immune modulation, Trends Immunol, 36 (2015) 419-427.

[21] K.A. Woodrow, K.M. Bennett, D.D. Lo, Mucosal vaccine design and delivery, Annu Rev Biomed Eng, 14 (2012) 17-46.

[22] C. Foged, B. Brodin, S. Frokjaer, A. Sundblad, Particle size and surface charge affect particle uptake by human dendritic cells in an in vitro model, Int J Pharm, 298 (2005) 315-322.

[23] B.D. Chithrani, A.A. Ghazani, W.C. Chan, Determining the size and shape dependence of gold nanoparticle uptake into mammalian cells, Nano Lett, 6 (2006) 662-668.

[24] A.E. Gregory, R. Titball, D. Williamson, Vaccine delivery using nanoparticles, Front Cell Infect Microbiol, 3 (2013) 13.

[25] S. Chadwick, C. Kriegel, M. Amiji, Nanotechnology solutions for mucosal immunization, Adv Drug Deliv Rev, 62 (2010) 394-407.

[26] B. Binjawadagi, V. Dwivedi, C. Manickam, K. Ouyang, Y. Wu, L.J. Lee, J.B. Torrelles, G.J. Renukaradhya, Adjuvanted poly(lactic-co-glycolic) acid nanoparticle-entrapped inactivated porcine reproductive and respiratory syndrome virus vaccine elicits cross-protective immune response in pigs, Int J Nanomedicine, 9 (2014) 679-694.

[27] J. Hiremath, K.I. Kang, M. Xia, M. Elaish, B. Binjawadagi, K. Ouyang, S. Dhakal, J. Arcos, J.B. Torrelles, X. Jiang, C.W. Lee, G.J. Renukaradhya, Entrapment of H1N1 Influenza Virus Derived Conserved Peptides in PLGA Nanoparticles Enhances T Cell Response and Vaccine Efficacy in Pigs, PLoS One, 11 (2016) e0151922.

[28] A. Ali, M. Khatri, L. Wang, Y.M. Saif, C.W. Lee, Identification of swine H1N2/pandemic H1N1 reassortant influenza virus in pigs, United States, Vet Microbiol, 158 (2012) 60-68.

[29] H.M. Yassine, M. Khatri, Y.J. Zhang, C.W. Lee, B.A. Byrum, J. O'Quin, K.A. Smith, Y.M. Saif, Characterization of triple reassortant H1N1 influenza A viruses from swine in Ohio, Vet Microbiol, 139 (2009) 132-139.

[30] L.A. van Leengoed, E.M. Kamp, A method for bronchoalveolar lavage in live pigs, Vet Q, 11 (1989) 65-72.

[31] M. Ganter, A. Hensel, Cellular variables in bronchoalveolar lavage fluids (BALF) in selected healthy pigs, Res Vet Sci, 63 (1997) 215-217.

[32] A.M. Collins, J. Rylance, D.G. Wootton, A.D. Wright, A.K. Wright, D.G. Fullerton, S.B. Gordon, Bronchoalveolar lavage (BAL) for research; obtaining adequate sample yield, J Vis Exp, (2014).

[33] L. Piriou-Guzylack, H. Salmon, Membrane markers of the immune cells in swine: an update, Vet Res, 39 (2008) 54.

[34] M. Khatri, V. Dwivedi, S. Krakowka, C. Manickam, A. Ali, L. Wang, Z. Qin, G.J. Renukaradhya, C.W. Lee, Swine influenza H1N1 virus induces acute inflammatory immune 
responses in pig lungs: a potential animal model for human H1N1 influenza virus, J Virol, 84 (2010) 11210-11218.

[35] G.J. Renukaradhya, K. Alekseev, K. Jung, Y. Fang, L.J. Saif, Porcine reproductive and respiratory syndrome virus-induced immunosuppression exacerbates the inflammatory response to porcine respiratory coronavirus in pigs, Viral Immunol, 23 (2010) 457-466.

[36] J.A. Richt, P. Lekcharoensuk, K.M. Lager, A.L. Vincent, C.M. Loiacono, B.H. Janke, W.H. Wu, K.J. Yoon, R.J. Webby, A. Solorzano, A. Garcia-Sastre, Vaccination of pigs against swine influenza viruses by using an NS1-truncated modified live-virus vaccine, J Virol, 80 (2006) 11009-11018.

[37] L.J. Reed, L. Muench, A Simple Method of Estimating Fifty Per Cent Endpoints, The American Journal of Hygiene, 27(3) (1938) 493-497.

[38] V. Dwivedi, C. Manickam, B. Binjawadagi, D. Joyappa, G.J. Renukaradhya, Biodegradable Nanoparticle-Entrapped Vaccine Induces Cross-Protective Immune Response against a Virulent Heterologous Respiratory Viral Infection in Pigs, PLoS One, 7 (2012) e51794.

[39] V. Dwivedi, C. Manickam, B. Binjawadagi, G.J. Renukaradhya, PLGA nanoparticle entrapped killed porcine reproductive and respiratory syndrome virus vaccine helps in viral clearance in pigs, Vet Microbiol, 166 (2013) 47-58.

[40] A. Rawat, Q.H. Majumder, F. Ahsan, Inhalable large porous microspheres of low molecular weight heparin: in vitro and in vivo evaluation, J Control Release, 128 (2008) 224-232.

[41] F.A. Zuckermann, Extrathymic CD4/CD8 double positive $\mathrm{T}$ cells, Vet Immunol Immunopathol, 72 (1999) 55-66.

[42] C. Thomas, A. Rawat, L. Hope-Weeks, F. Ahsan, Aerosolized PLA and PLGA Nanoparticles Enhance Humoral, Mucosal and Cytokine Responses to Hepatitis B Vaccine, Mol Pharm, 8 (2011) 405-415.

[43] T.E. Greenway, J.H. Eldridge, G. Ludwig, J.K. Staas, J.F. Smith, R.M. Gilley, S.M. Michalek, Induction of protective immune responses against Venezuelan equine encephalitis (VEE) virus aerosol challenge with microencapsulated VEE virus vaccine, Vaccine, 16 (1998) 1314-1323.

[44] M.J. Shephard, D. Todd, B.M. Adair, A.L. Po, D.P. Mackie, E.M. Scott, Immunogenicity of bovine parainfluenza type 3 virus proteins encapsulated in nanoparticle vaccines, following intranasal administration to mice, Res Vet Sci, 74 (2003) 187-190.

[45] H.M. Yassine, J.C. Boyington, P.M. McTamney, C.J. Wei, M. Kanekiyo, W.P. Kong, J.R. Gallagher, L. Wang, Y. Zhang, M.G. Joyce, D. Lingwood, S.M. Moin, H. Andersen, Y. Okuno, S.S. Rao, A.K. Harris, P.D. Kwong, J.R. Mascola, G.J. Nabel, B.S. Graham, Hemagglutinin-stem nanoparticles generate heterosubtypic influenza protection, Nat Med, 21 (2015) 1065-1070.

[46] Q. Liu, X. Zheng, C. Zhang, X. Shao, X. Zhang, Q. Zhang, X. Jiang, Conjugating influenza a $(\mathrm{H} 1 \mathrm{~N} 1)$ antigen to $n$-trimethylaminoethylmethacrylate chitosan nanoparticles improves the immunogenicity of the antigen after nasal administration, J Med Virol, 87 (2015) 1807-1815.

[47] M. Singh, M. Briones, D.T. O'Hagan, A novel bioadhesive intranasal delivery system for inactivated influenza vaccines, J Control Release, 70 (2001) 267-276.

[48] F. Mansoor, B. Earley, J.P. Cassidy, B. Markey, S. Doherty, M.D. Welsh, Comparing the immune response to a novel intranasal nanoparticle PLGA vaccine and a commercial BPI3V vaccine in dairy calves, BMC Veterinary Research, 11 (2015) 1-11.

[49] B. Binjawadagi, V. Dwivedi, C. Manickam, K. Ouyang, J.B. Torrelles, G.J. Renukaradhya, An innovative approach to induce cross-protective immunity against porcine reproductive and 
respiratory syndrome virus in the lungs of pigs through adjuvanted nanotechnology-based vaccination, Int J Nanomedicine, 9 (2014) 1519-1535.

[50] T.T. Beaudette, E.M. Bachelder, J.A. Cohen, A.C. Obermeyer, K.E. Broaders, J.M. Frechet, E.S. Kang, I. Mende, W.W. Tseng, M.G. Davidson, E.G. Engleman, In vivo studies on the effect of co-encapsulation of CpG DNA and antigen in acid-degradable microparticle vaccines, Mol Pharm, 6 (2009) 1160-1169.

[51] S. Jong, G. Chikh, L. Sekirov, S. Raney, S. Semple, S. Klimuk, N. Yuan, M. Hope, P. Cullis, Y. Tam, Encapsulation in liposomal nanoparticles enhances the immunostimulatory, adjuvant and anti-tumor activity of subcutaneously administered CpG ODN, Cancer Immunology, Immunotherapy, 56 (2007) 1251-1264.

[52] V. Manolova, A. Flace, M. Bauer, K. Schwarz, P. Saudan, M.F. Bachmann, Nanoparticles target distinct dendritic cell populations according to their size, European Journal of Immunology, 38 (2008) 1404-1413.

[53] F. Blank, P.A. Stumbles, E. Seydoux, P.G. Holt, A. Fink, B. Rothen-Rutishauser, D.H. Strickland, C. von Garnier, Size-dependent uptake of particles by pulmonary antigen-presenting cell populations and trafficking to regional lymph nodes, Am J Respir Cell Mol Biol, 49 (2013) 67-77.

[54] W. Jiang, R.K. Gupta, M.C. Deshpande, S.P. Schwendeman, Biodegradable poly(lactic-coglycolic acid) microparticles for injectable delivery of vaccine antigens, Adv Drug Deliv Rev, 57 (2005) 391-410.

[55] D.A. Blair, D.L. Turner, T.O. Bose, Q.M. Pham, K.R. Bouchard, K.J. Williams, J.P. McAleer, L.S. Cauley, A.T. Vella, L. Lefrancois, Duration of antigen availability influences the expansion and memory differentiation of T cells, J Immunol, 187 (2011) 2310-2321.

[56] J.E. Babensee, A. Paranjpe, Differential levels of dendritic cell maturation on different biomaterials used in combination products, Journal of Biomedical Materials Research Part A, 74A (2005) 503-510.

[57] M. Yoshida, J.E. Babensee, Differential effects of agarose and poly(lactic-co-glycolic acid) on dendritic cell maturation, J Biomed Mater Res A, 79 (2006) 393-408.

[58] M. Yoshida, J.E. Babensee, Poly(lactic-co-glycolic acid) enhances maturation of human monocyte-derived dendritic cells, J Biomed Mater Res A, 71 (2004) 45-54.

[59] M. Yoshida, J. Mata, J.E. Babensee, Effect of poly(lactic-co-glycolic acid) contact on maturation of murine bone marrow-derived dendritic cells, J Biomed Mater Res A, 80 (2007) 712.

[60] P. Elamanchili, M. Diwan, M. Cao, J. Samuel, Characterization of poly(d,1-lactic-coglycolic acid) based nanoparticulate system for enhanced delivery of antigens to dendritic cells, Vaccine, 22 (2004) 2406-2412.

[61] R. Arens, S.P. Schoenberger, Plasticity in programming of effector and memory CD8 T-cell formation, Immunol Rev, 235 (2010) 190-205.

[62] H. Shen, A.L. Ackerman, V. Cody, A. Giodini, E.R. Hinson, P. Cresswell, R.L. Edelson, W.M. Saltzman, D.J. Hanlon, Enhanced and prolonged cross-presentation following endosomal escape of exogenous antigens encapsulated in biodegradable nanoparticles, Immunology, 117 (2006) 78-88.

[63] T. Gerelchuluun, Y.-H. Lee, Y.-R. Lee, S.-A. Im, S. Song, J.S. Park, K. Han, K. Kim, C.-K. Lee, Dendritic cells process antigens encapsulated in a biodegradable polymer, poly(D,L-lactideco-glycolide), via an alternate class I MHC processing pathway, Archives of Pharmacal Research, 30 (2007) 1440-1446. 
[64] Y.-W. Yang, P.Y.-J. Hsu, The effect of poly(d,l-lactide-co-glycolide) microparticles with polyelectrolyte self-assembled multilayer surfaces on the cross-presentation of exogenous antigens, Biomaterials, 29 (2008) 2516-2526.

[65] J. Panyam, W.Z. Zhou, S. Prabha, S.K. Sahoo, V. Labhasetwar, Rapid endo-lysosomal escape of poly(DL-lactide-co-glycolide) nanoparticles: implications for drug and gene delivery, FASEB J, 16 (2002) 1217-1226.

[66] M. Thome, W. Hirt, E. Pfaff, M.J. Reddehase, A. Saalmuller, Porcine T-cell receptors: molecular and biochemical characterization, Vet Immunol Immunopathol, 43 (1994) 13-18.

[67] W. Gerner, T. Kaser, A. Saalmuller, Porcine T lymphocytes and NK cells - An update, Dev Comp Immunol, 33 (2009) 310-320.

[68] S.C. Talker, T. Kaser, K. Reutner, C. Sedlak, K.H. Mair, H. Koinig, R. Graage, M. Viehmann, E. Klingler, A. Ladinig, M. Ritzmann, A. Saalmuller, W. Gerner, Phenotypic maturation of porcine NK- and T-cell subsets, Dev Comp Immunol, 40 (2013) 51-68.

[69] A. Saalmuller, T. Werner, V. Fachinger, T-helper cells from naive to committed, Vet Immunol Immunopathol, 87 (2002) 137-145.

[70] S. Hamdy, O. Molavi, Z. Ma, A. Haddadi, A. Alshamsan, Z. Gobti, S. Elhasi, J. Samuel, A. Lavasanifar, Co-delivery of cancer-associated antigen and Toll-like receptor 4 ligand in PLGA nanoparticles induces potent CD8+ T cell-mediated anti-tumor immunity, Vaccine, 26 (2008) 5046-5057.

[71] Z. Zhang, S. Tongchusak, Y. Mizukami, Y.J. Kang, T. Ioji, M. Touma, B. Reinhold, D.B. Keskin, E.L. Reinherz, T. Sasada, Induction of anti-tumor cytotoxic T cell responses through PLGA-nanoparticle mediated antigen delivery, Biomaterials, 32 (2011) 3666-3678.

[72] D.J. Hanlon, P.B. Aldo, L. Devine, A.B. Alvero, A.K. Engberg, R. Edelson, G. Mor, Enhanced Stimulation of Anti-Ovarian Cancer CD8+ T Cells by Dendritic Cells Loaded with Nanoparticle Encapsulated Tumor Antigen, American Journal of Reproductive Immunology, 65 (2011) 597-609.

[73] R.M. Welsh, M.-Y. Lin, B.L. Lohman, S.M. Varga, C.C. Zarozinski, L.K. Selin, $\alpha \beta$ and $\gamma \delta$ T-cell networks and their roles in natural resistance to viral infections, Immunological Reviews, 159 (1997) 79-93.

[74] M.R. Olin, L. Batista, Z. Xiao, S.A. Dee, M.P. Murtaugh, C.C. Pijoan, T.W. Molitor, Gammadelta lymphocyte response to porcine reproductive and respiratory syndrome virus, Viral Immunol, 18 (2005) 490-499.

[75] M. Zaman, M.F. Good, I. Toth, Nanovaccines and their mode of action, Methods, 60 (2013) 226-231.

[76] A.J. Almeida, H.O. Alpar, Nasal delivery of vaccines, J Drug Target, 3 (1996) 455-467.

[77] P. Moss, Cellular immune responses to influenza, Developments in biologicals, 115 (2003) 31-37.

[78] N.L. La Gruta, S.J. Turner, T cell mediated immunity to influenza: mechanisms of viral control, Trends in Immunology, 35 (2014) 396-402.

[79] A. Bot, S. Bot, C.A. Bona, Protective Role of Gamma Interferon during the Recall Response to Influenza Virus, Journal of Virology, 72 (1998) 6637-6645.

[80] G.J. Renukaradhya, B. Narasimhan, S.K. Mallapragada, Respiratory nanoparticle-based vaccines and challenges associated with animal models and translation, J Control Release, 219 (2015) 622-631. 
[81] V.L. Herrmann, C. Hartmayer, O. Planz, M. Groettrup, Cytotoxic T cell vaccination with PLGA microspheres interferes with influenza A virus replication in the lung and suppresses the infectious disease, J Control Release, 216 (2015) 121-131. 


\section{Figure legends}

Fig. 1: In vitro physical characterization of PLGA-KAg NPs and their role in maturation of APCs. (A) Surface morphology of PLGA-KAg (10 Kx magnification). (B) Size distribution of PLGA-KAg. Percentages were calculated based on determining the size of 200 NPs. (C) In vitro protein release profile of PLGA-KAg over a period of 4 weeks. Effect of treatment of PLGAKAg on the expression of costimulatory molecule CD80/86 on pig (D) MoDCs and (E) macrophages. CD172a is a porcine pan-myeloid marker and it is expressed on the surface of both dendritic cells and macrophages of pigs. Hence, CD80/86 expression is shown as the percentage of CD172 $\mathrm{a}^{+}$dendritic cells and macrophages in Fig. 1D and 1E, respectively. Data were analyzed by one way ANOVA followed by Tukey’s post-hoc test. Asterisk refers to statistical significant difference between the two indicated pig groups $(* \mathrm{p}<0.05 ; * * \mathrm{p}<0.01$; and $* * *$ $\mathrm{p}<0.001)$.

Fig. 2: Cellular and humoral immune responses in PLGA-KAg vaccinated pigs pre-challenge. Isolated PBMCs after prime-boost vaccination at DPV 35 / DPC 0 were restimulated and specific lymphocyte proliferation was determined against (A) homologous vaccine virus (SwIV H1N2) and (B) heterologous challenge virus (SwIV H1N1). Frequencies of (C) $\mathrm{CD}^{+} \mathrm{CD}^{+} \mathrm{CD} 8 \alpha^{+}$cells; (D) $\mathrm{CD}^{+} \mathrm{CD}^{+} \mathrm{CD} 8 \alpha \beta^{+}$cells; and (E) $\mathrm{CD}^{+} \delta^{+} \gamma \delta \mathrm{T}$ cells in PBMCs were determined at DPC 0 by flow cytometry analysis. Data were analyzed by one way ANOVA followed by Tukey’s posthoc test. Asterisk refers to statistical difference between two indicated pig groups $(*$ refers $\mathrm{p}<0.05 ; * *$ refers $\mathrm{p}<0.01 ;$ and $* * *$ refers $\mathrm{p}<0.001)$

Fig. 3: Intranasal route of PLGA-KAg vaccination reduced the clinical flu caused by a heterologous virus challenge in pigs. Pigs were vaccinated with KAg or PLGA-KAg intranasally as a mist using a custom built multidose vaccine delivery device. Fig. 4. Reduced lung lesions in 
pigs vaccinated with PLGA-KAg and virulent virus challenged. A representative lung picture of every experimental pig groups is shown: (A) Gross lung lesions of consolidation are indicated by arrows; (B) microscopic lung sections stained by H\&E; and (C) immunohistochemistry analysis of lung sections for SwIV antigens.

Fig. 5. A representative flow cytometry plots showing the gatting pattern of pig lymphocytes. PBMCs isolated at DPC 6 from PLGA-KAg vaccinated and virus challenged pigs were restimuatled with SwIV H1N1 and treated with Golgiplug/block, and immunostained using pig specific lymphocyte surface markers followed by intracellular IFN $\gamma$, and estimated the frequency of activated (IFN $\left.\gamma^{+}\right)$lymphcocyte subpopulations. Gating pattern of isotype and lymphocyte specific markers stained with CD3غ, CD $4 \alpha, \mathrm{CD} 8 \alpha, \mathrm{CD} 8 \beta$ and IFN $\gamma$ to identify the frequency of $\mathrm{CD} 3^{-} \mathrm{IFN} \gamma^{+}, \mathrm{CD} 3^{-} \mathrm{CD} 4^{-} \mathrm{CD} 8 \alpha^{+} \mathrm{IFN} \gamma^{+}, \mathrm{CD}^{+}{ }^{+} \mathrm{IFN} \gamma^{+}, \mathrm{CD}^{+} \mathrm{CD}^{+} \mathrm{CD} 8 \alpha^{-} \mathrm{IFN} \gamma^{+}$, $\mathrm{CD}^{+}{ }^{+} \mathrm{CD} 4^{+} \mathrm{CD} 8 \alpha^{+} \mathrm{IFN} \gamma^{+}$and $\mathrm{CD}^{+} \mathrm{CD} 4{ }^{-} \mathrm{CD} 8 \alpha \beta^{+} \mathrm{IFN} \gamma^{+}$cells are shown.

Fig. 6. Lymphocytes recall response in PLGA-KAg vaccinated and virus challenged pigs were significantly augmented. On the day of necropsy (DPC 6) isolated PBMCs were restimulated with vaccine or challenge virus and the frequency of activated (IFN $\left.\gamma^{+}\right)$lymphocytes were determined by flow cytometry. Average frequency of lymphocytes: (A) $\mathrm{CD}^{+} \mathrm{IFN}^{+}$; (B) $\mathrm{CD}^{-}$ IFN $\gamma^{+}$; (C) $\mathrm{CD}^{+}{ }^{+} \mathrm{CD} 4^{+} \mathrm{CD} 8 \alpha^{+} \mathrm{IFN} \gamma^{+}$; (D) $\mathrm{CD}^{+} \mathrm{CD}^{+} \mathrm{CD} 8 \alpha{ }^{-} \mathrm{IFN} \gamma^{+}$; (E) $\mathrm{CD} 3^{+} \mathrm{CD} 4 \mathrm{CD} 8 \alpha \beta^{+} \mathrm{IFN} \gamma^{+}$; and (F) $\mathrm{CD}^{-} \mathrm{CD} 4{ }^{-} \mathrm{CD} 8 \alpha^{+} \mathrm{IFN} \gamma^{+}$from all the experimental pig groups were quantified. Each bar indicates the average frequency of indicated lymphcocyte subset of 7 or 9 pigs \pm SEM. Data were analyzed by one way ANOVA followed by Tukey's post-hoc test. Asterisk refers to statistical significant difference between the two indicated pig groups $(* \mathrm{p}<0.05 ; * * \mathrm{p}<0.01$; and $* * * \mathrm{p}<0.001)$ 
Fig. 7. Enhanced IFN $\gamma$ secretion and recall $\mathrm{T}$ cell response in PLGA-KAg vaccinated and virus challenged pigs. PBMCs isolated at DPC 6 were restimulated with vaccine or challenge virus for 3 days. (A) Cell culture supernatant was harvested and determined the levels of secreted IFN $\gamma$ by ELISA. The recall cellular response in PBMCs of only PLGA-KAg vaccinated pigs restimulated (SwIV H1N1 or H1N2) or unstimulated (cell control, CC) are shown in terms of (B) secreted IFN $\gamma$ in cell culture supernatant. Each bar indicates the average frequency of indicated lymphcocyte subset of 7 or 9 pigs \pm SEM. Data were analyzed by one way ANOVA followed by Tukey’s post-hoc test. Asterisk refers to statistical significant difference between the two indicated pig groups $(* \mathrm{p}<0.05 ; * * \mathrm{p}<0.01)$. 
Fig. 1

A

B

C
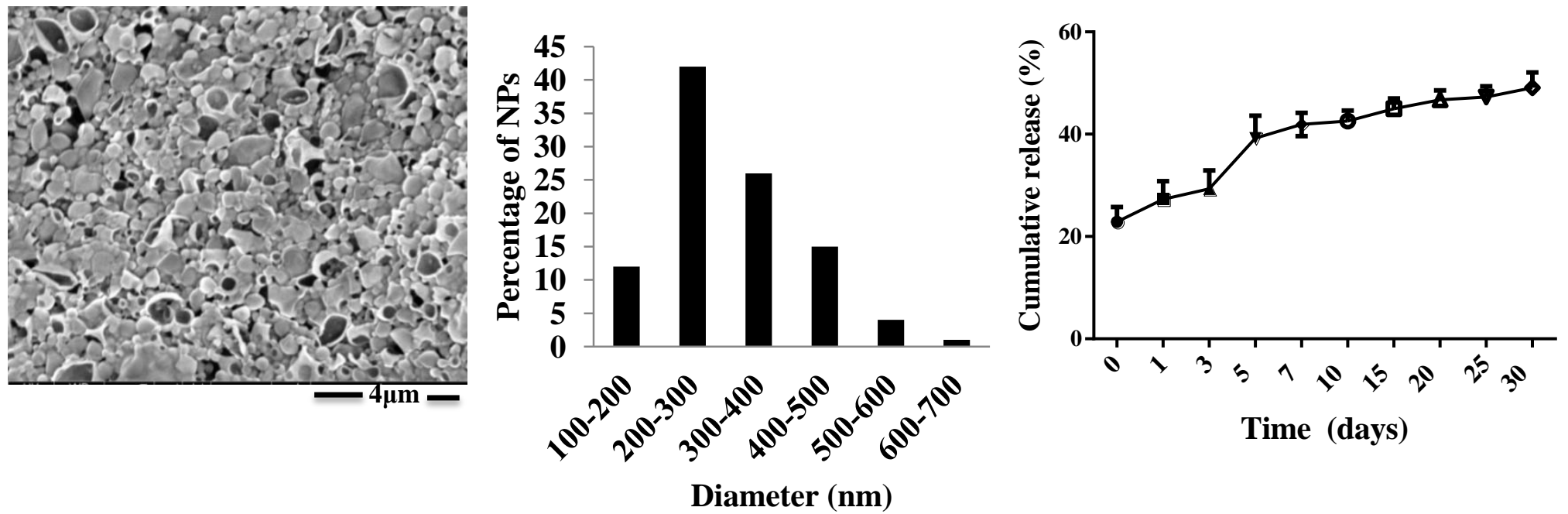

D CD80/86 expression on MoDCs

E CD80/86 expression of M $\$ \mathrm{~s}$
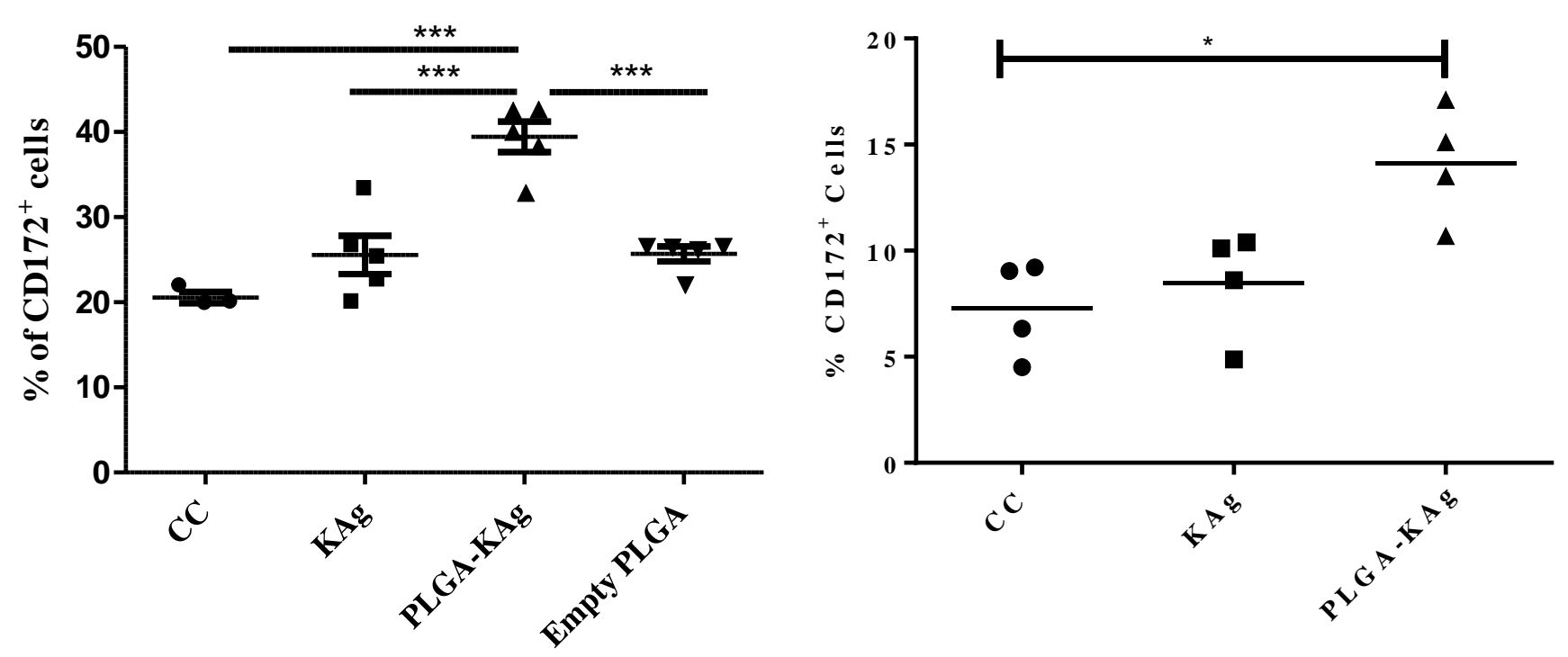
Fig. 2
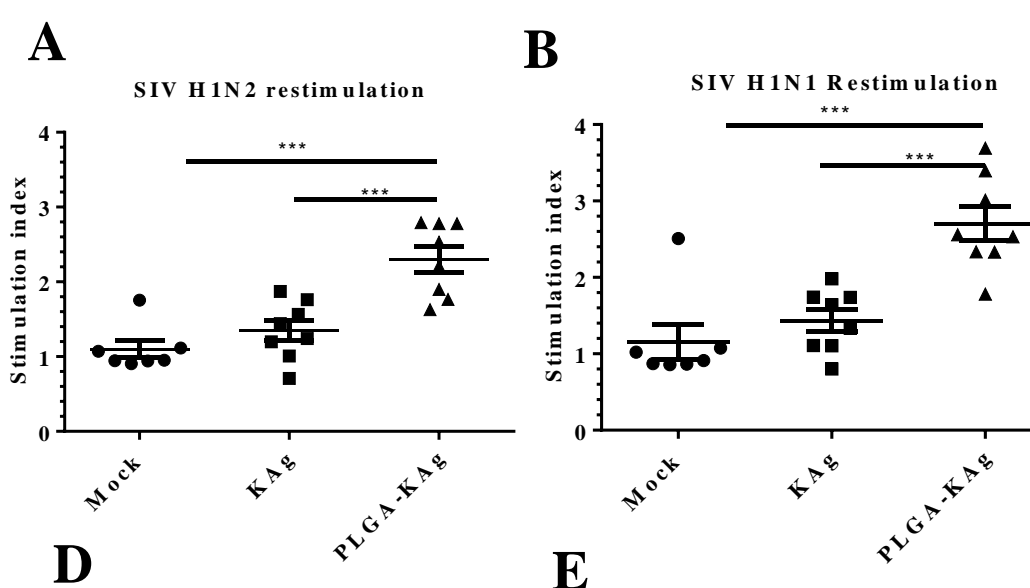

C
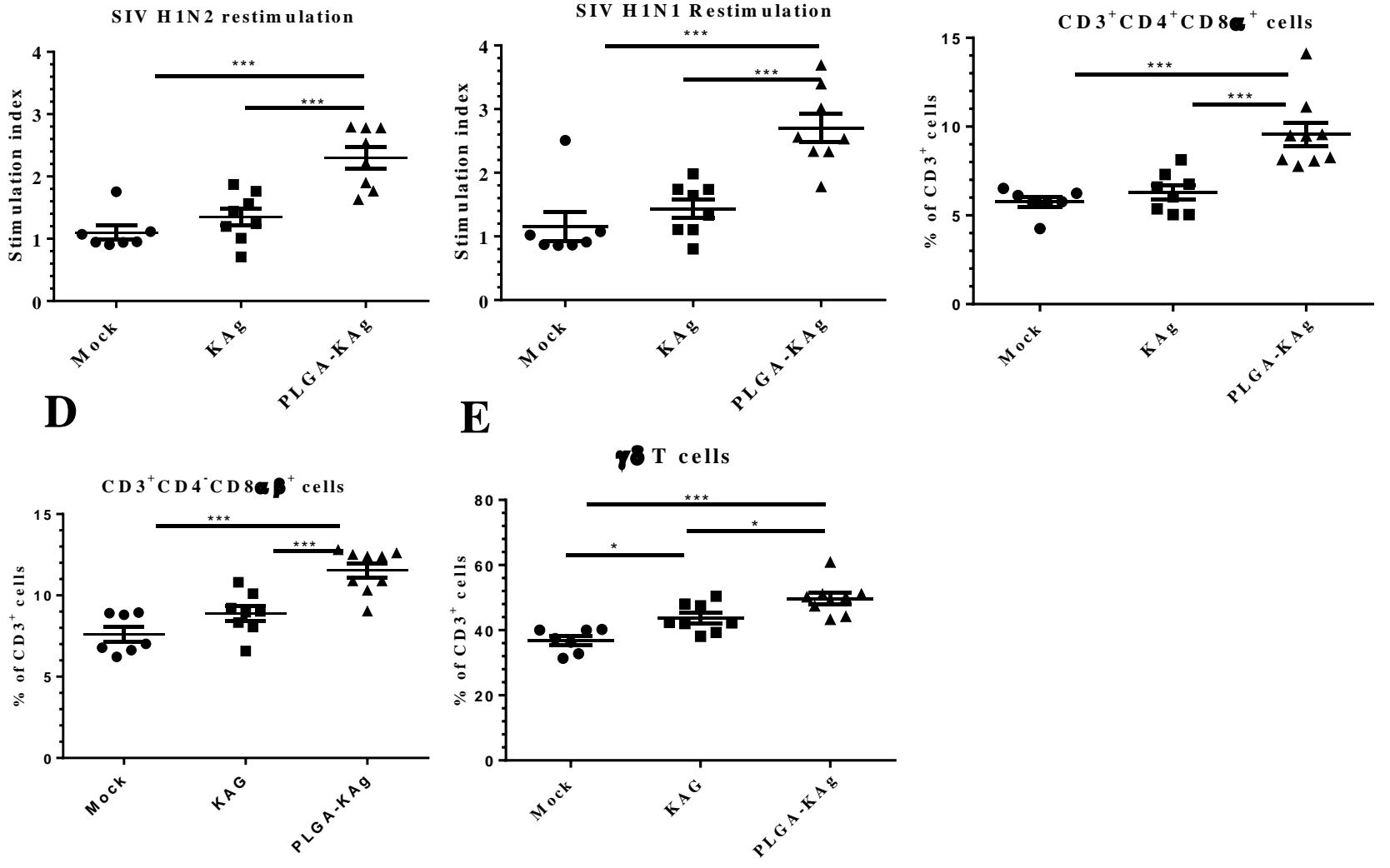
Fig. 3
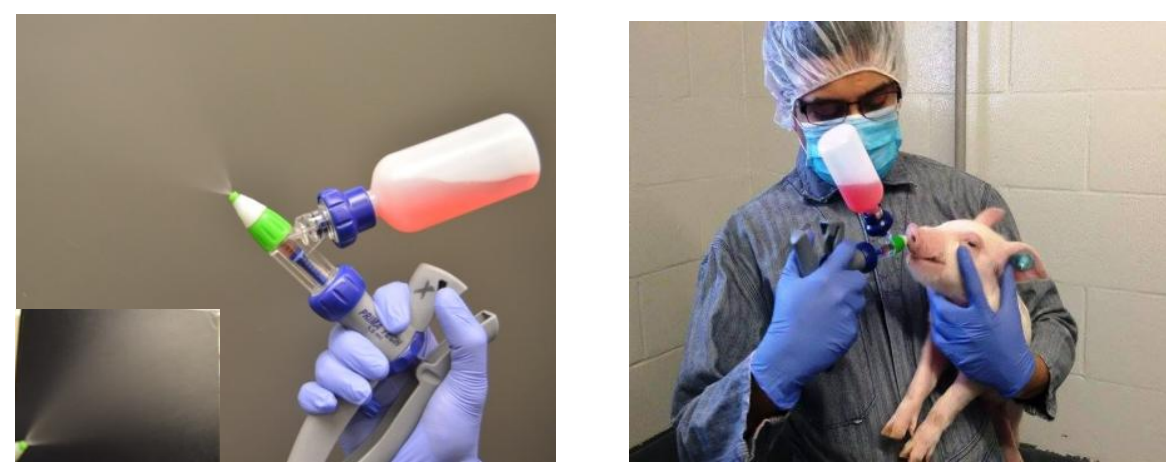
Fig. 4
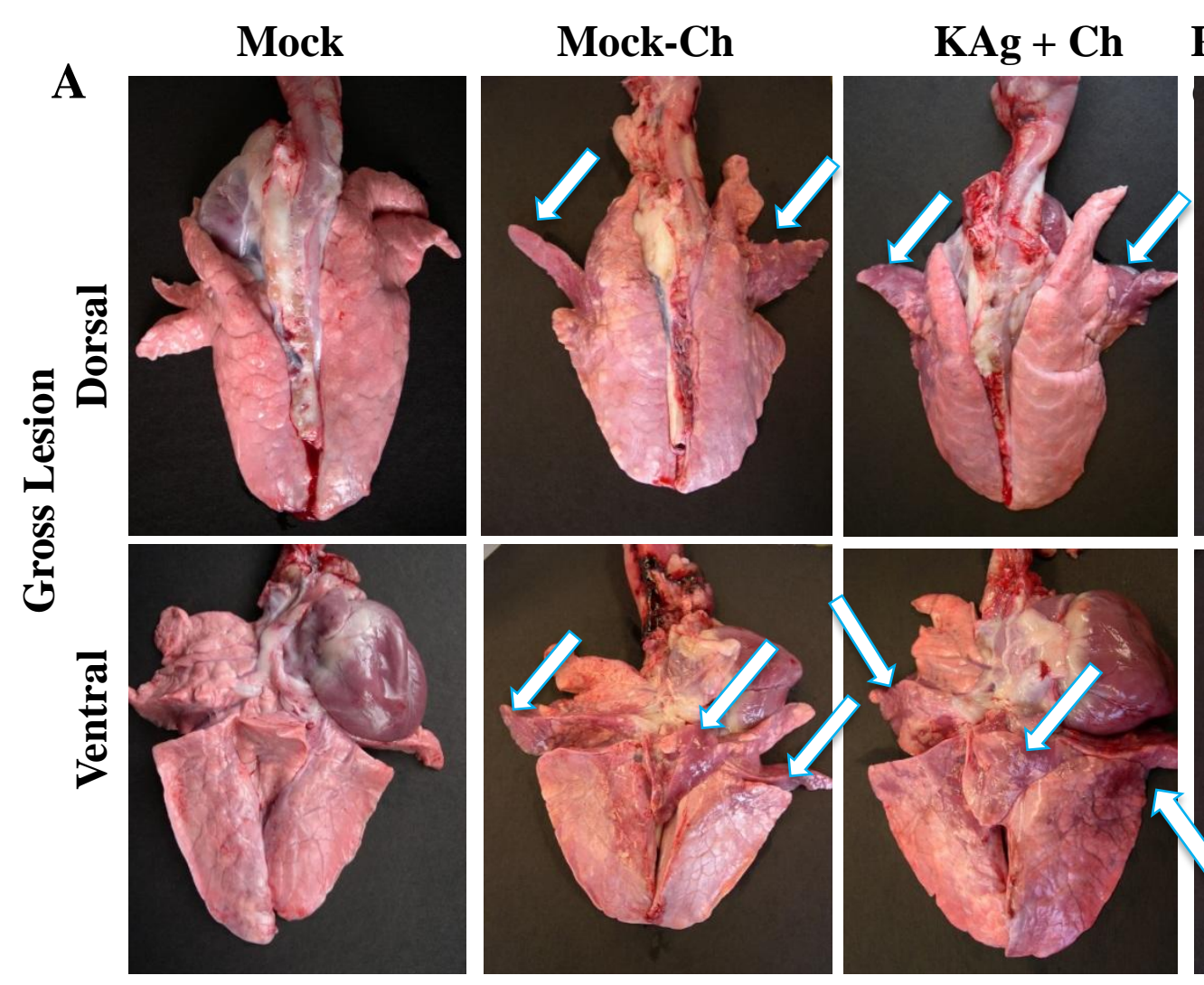

PLGA-KAg +
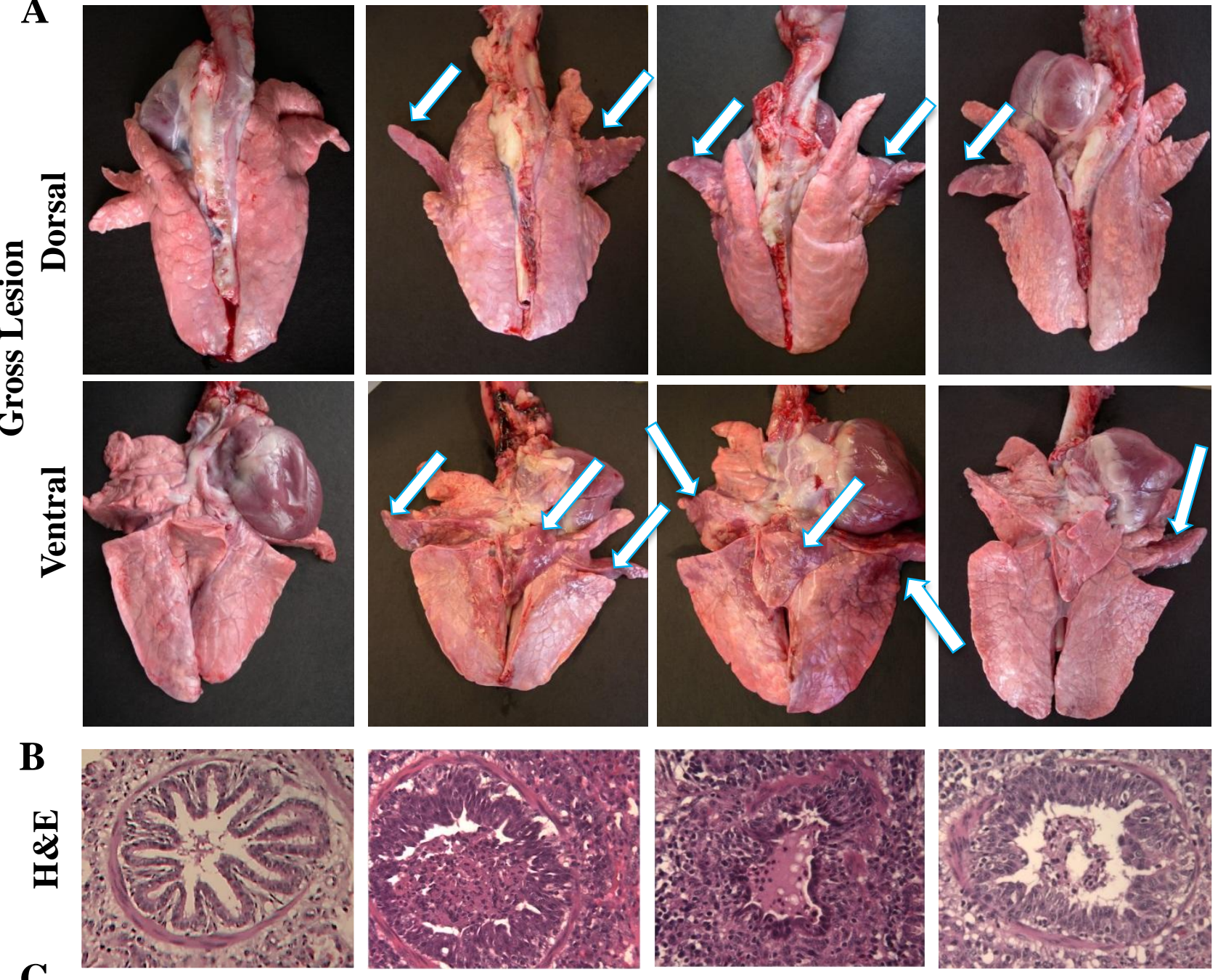

C Bzind

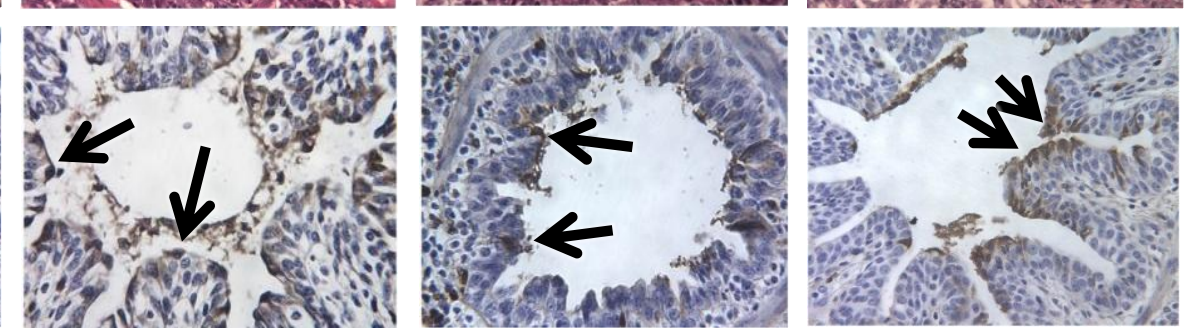


Fig. 5

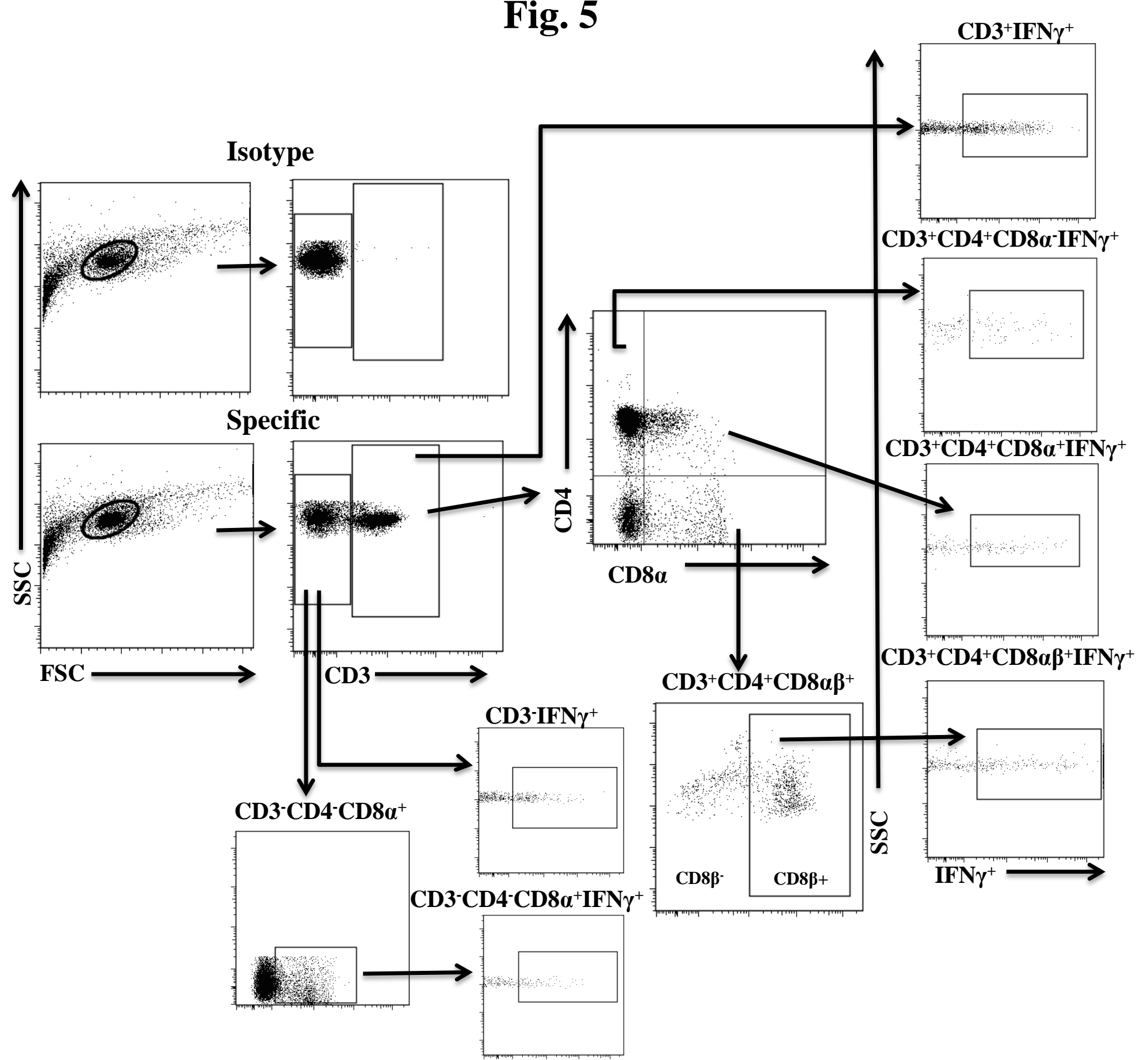


Fig. 6
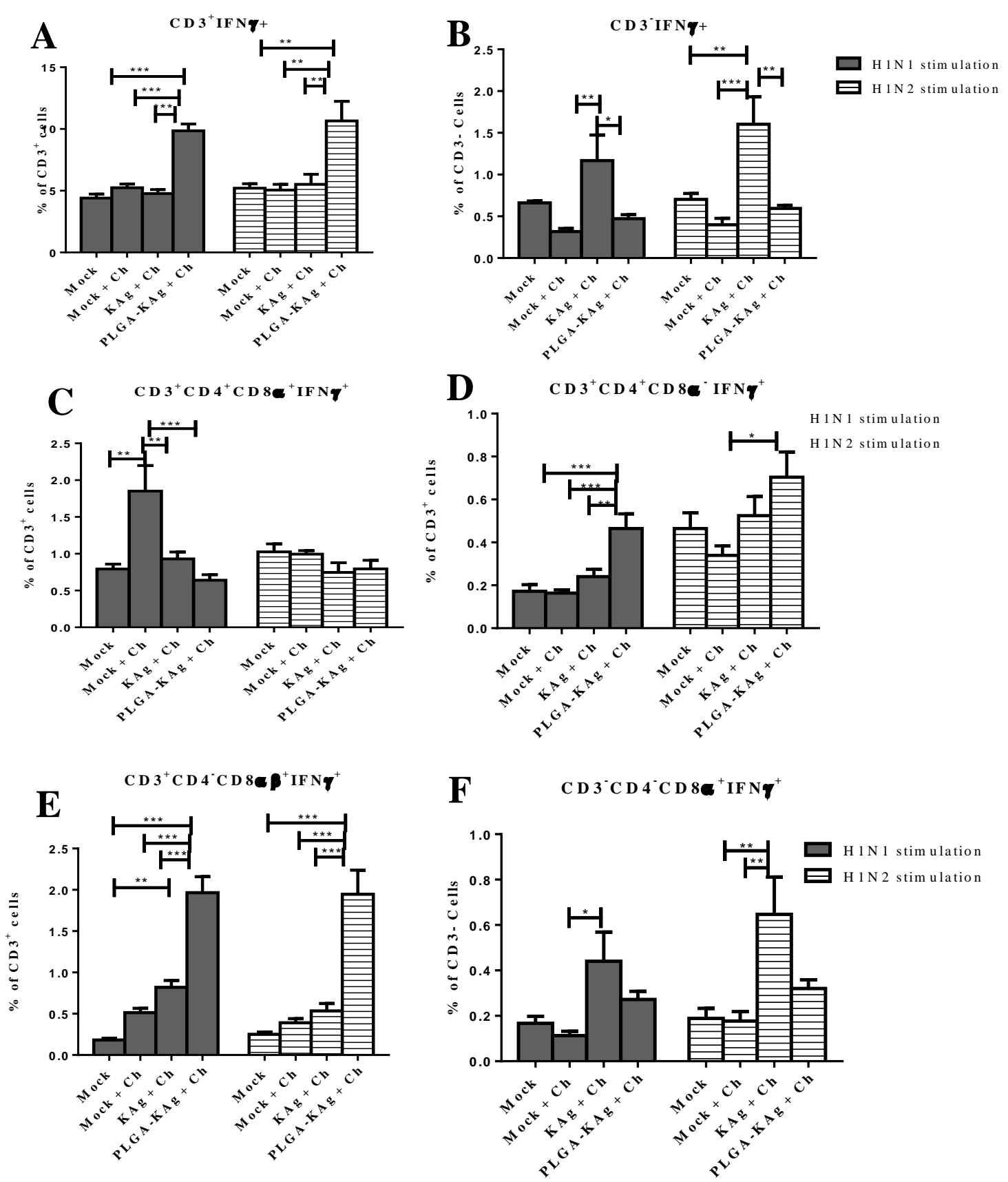
Fig. 7

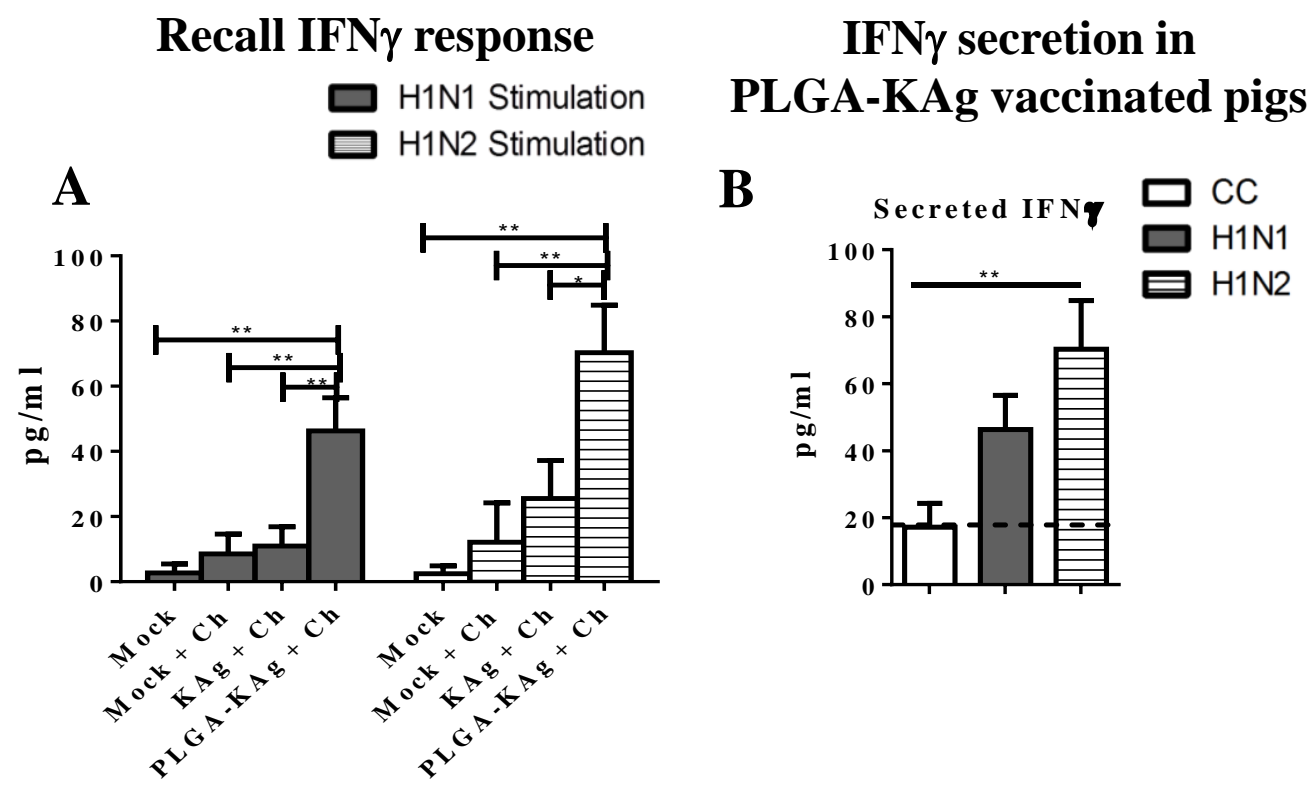




\section{Graphical abstract}

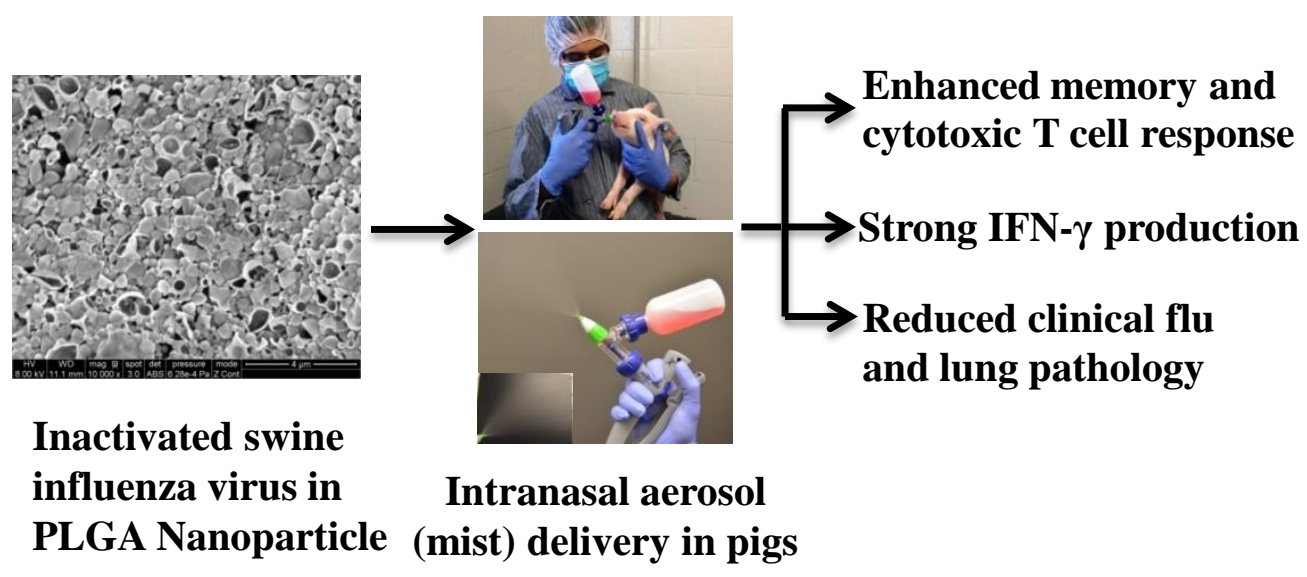

